\title{
Boundary Layer Transition Flight Experiment Overview
}

\author{
Karen T. Berger ${ }^{1}$ \\ NASA Langley Research Center, Hampton, VA \\ Brian P. Anderson ${ }^{2}$, Charles H. Campbell ${ }^{3}$, Michael T. Garske ${ }^{4}$, Luis A. Saucedo ${ }^{4}$ \\ NASA Johnson Space Center, Houston, TX \\ Gerald R. Kinder ${ }^{5}$ \\ The Boeing Company, Huntington Beach, CA \\ Ann M. Micklos ${ }^{6}$ \\ United Space Alliance, NASA Kennedy Space Center, FL
}

In support of the Boundary Layer Transition Flight Experiment (BLT FE) Project, a manufactured protuberance tile was installed on the port wing of Space Shuttle Orbiter Discovery for STS-119, STS-128, STS-131 and STS-133 as well as Space Shuttle Endeavour for STS-134. Additional instrumentation was installed in order to obtain more spatially resolved measurements downstream of the protuberance. This paper provides an overview of the BLT FE Project with emphasis on the STS-131 and STS-133 results. A high-level overview of the in-situ flight data is presented, along with a summary of the comparisons between pre- and post-flight analysis predictions and flight data. Comparisons show that empirically correlated predictions for boundary layer transition onset time closely match the flight data, while predicted surface temperatures were significantly higher than observed flight temperatures. A thermocouple anomaly observed on a number of the missions is discussed as are a number of the mitigation actions that will be taken on the final flight, STS-134, including potential alterations of the flight trajectory and changes to the flight instrumentation.

$\begin{array}{ll}\text { Symbols } & \\ B F_{C F D} & \text { Heating augmentation ("bump") factor predicted by CFD, dimensionless } \\ k & \text { Adjustment ("knockdown") factor, dimensionless } \\ \mathrm{M}_{e} & \text { Mach number at the edge of the boundary layer, dimensionless } \\ \operatorname{Re}_{\theta} & \text { Reynolds number based on momentum thickness, dimensionless } \\ \dot{q} & \text { Heat flux, Btu/ft }{ }^{2} \text {-sec } \\ \dot{q}_{X F 0002} & \text { Heat flux prediction provided by XF0002, Btu/ft }{ }^{2} \text {-sec } \\ \sigma & \text { Standard deviation }\end{array}$

\section{Introduction}

The amount of thermal protection system (TPS) required for a safe and successful entry is one of the major driving factors in the design and weight of any vehicle entering a planetary atmosphere. The time during the entry at which the boundary layer transitions from laminar to turbulent flow is a major factor in the TPS sizing. The study of boundary layer transition (BLT) has been a significant effort for many decades, but the specific physics-based mechanisms that cause hypersonic BLT are poorly understood. This lack of understanding hinders designers in making accurate predictions of when the boundary layer will become turbulent and affects the sizing and the understanding of TPS robustness. If the geometry of a vehicle is known, engineers can obtain ground-test data from wind tunnels to develop engineering correlations ${ }^{1-4}$. However, one of the major weaknesses in a ground-based correlation approach is lack of understanding of the differences between wind tunnel and flight environments and how those differences affect

\footnotetext{
${ }^{1}$ BLT Flight Experiment Principal Investigator, Aerothermodynamics Branch, M/S 408A, AIAA Senior member

${ }^{2}$ Aerospace Engineer, Applied Aeroscience and CFD Branch, M/C EG3

${ }^{3}$ Deputy BLT Flight Experiment Principal Investigator, Applied Aeroscience and CFD Branch, M/C EG3, AIAA Associate Fellow

${ }^{4}$ BLT Flight Experiment Project Manager, Orbiter Project Office, M/C MV6

${ }^{5}$ Senior Engineer/ Scientist, Integrated Defense Systems/Space Exploration, Flight Sciences/Aerodynamics

${ }^{6}$ Orbiter Project Manager, Projects and Requirements Integration Office, USK-246, AIAA Senior member
} 
BLT. In addition to the difficulties in predicting the onset of BLT, hypersonic turbulent heating predictions have also proven to be very challenging in many cases. Very little data exists to verify turbulent heating prediction models at low Reynolds numbers and hypersonic conditions.

Following STS-107, the Orbiter Damage Assessment Team (DAT) was established with a charter to assess the effects of ascent and on-orbit damage and impacts upon the ability to perform safe re-entry ${ }^{5}$. A substantial testing and analytical tool development activity was undertaken to characterize the aeroheating, thermal, and stress implications of damage on the Orbiter temperatures, tile factors of safety, and structural margins. The more notable aeroheating tools developed included the BLT Tool ${ }^{3,}{ }^{5-7}$ and the Cavity Heating Tool ${ }^{5,8,9,10}$. In addition, the ability to rapidly produce Computational Fluid Dynamics (CFD) simulations of damage scenarios was also developed ${ }^{11,12}$. Many of these capabilities are now also being utilized in support of the NASA Orion/Multi-Purpose Crew Vehicle effort (MPCV).

During STS-114 $4^{13}$, an unprecedented repair spacewalk was performed to remove two protruding gap fillers because the risks associated with the uncertainties in early BLT predictions and resulting heating effects were determined to be higher than the risks for spacewalk itself. As a result of these uncertainties with BLT and turbulent heating predictions, a flight test using a protuberance on the Orbiter to purposefully trip the boundary layer at a prescribed Mach number was proposed in November $2006^{14}$. The flight experiment was ultimately approved and funded by the Space Shuttle Program (SSP) and the NASA Engineering and Safety Center (NESC). In addition, The NASA Fundamental Aeronautics Program Hypersonics Project has sponsored a number of research efforts in part motivated by this flight experiment activity ${ }^{1,6,15,16,17}$.

Many motivations exist ${ }^{5}$ to obtain flight test data of this kind including a strong desire to obtain data to improve modeling capabilities and increase the potential for physics-based understanding. Although early proposals included installing experiment hardware on all three Orbiter vehicles, the protuberance tile and augmented instrumentation package was initially only installed on one Orbiter, OV-103 (Discovery). Later in the flight experiment effort, after the first three flights and while in preparation for the fourth and final flight of the experiment, a proposal was put forward and approved to add the protuberance tile to an additional Orbiter, OV-105 (Endeavour). The proposed implementation included a scaled back instrumentation package and the same protuberance height as the final flight for OV-103.

Participation in the planning and execution of the BLT FE included personnel from Johnson Space Center (JSC), Kennedy Space Center (KSC), Langley Research Center (LaRC), Ames Research Center (ARC), the United Space Alliance (USA), Boeing Houston and Boeing Huntington Beach. Disciplines involved included experts in hardware, ground operations, aerothermodynamics, aerodynamics, flight controls, thermal analysis, structural analysis, trajectory design, operations, loads \& dynamics, impact test \& analysis, instrumentation, avionics, software, materials \& processes, manufacturing, Safety \& Mission Assurance, and robotics. Representatives from the Astronaut Crew Office also participated.

Because the number of flights remaining in the SSP manifest was very limited at the time the effort was being formulated, implementation of the flight experiment required rapid planning. There were only about four flights left in the manifest for each Orbiter ca. 2007. Preliminary reviews were held in June 2007 to formally define the flight test scope and review initial plans. In order for the flight experiment protuberance and augmented instrumentation to be implemented, reviews and concurrence from all relevant entities in the Space Shuttle Program was necessary. Of significance note was that in these reviews not only the technical issues required addressing. Perceptions of risk and related issues involving the performance of a re-entry experiment on an operational vehicle also needed to be resolved. After adequately addressing the concerns and issues for the first flight, program approval for installation of the protuberance tile was obtained in the fall of 2008. Re-entry for the first flight of the experiment, STS-119, occurred on March 28, 2009. Re-entry for the second flight experiment, STS-128, occurred on September 11, 2009. Reentry for the third flight experiment, STS-131, occurred on April 20, 2010 and for the fourth flight, STS-133, on March 9, 2011. Data from the fifth flight, STS-134, with a June 1, 2011 re-entry is currently being assessed.

An activity complementary to the BLT FE led by NASA LaRC was also undertaken to image the Orbiter during re-entry using infrared detectors. The Hypersonic Thermodynamic Infrared Measurements (HYTHIRM) ${ }^{18,19}$ team imaged the Orbiter on STS-119, STS-128, STS-131 and 
STS-133 (in addition to the non-BLT FE flights STS-125 and STS-132). The team also supported STS-134.

A very brief overview of the flight experiment planning and first two flights, STS-119 and STS128 are provided in the sections that follow, with additional information available in reference 15. The third (STS-131) and fourth (STS-133) flights are then discussed in detail, as well as the planning for the fifth and final flight, STS-134.

\section{Experiment Design Overview}

The following includes pertinent information for the STS-131 and STS-133 flights as well as the planning for STS-134. A discussion of the experimental design can be found in Reference 15 and includes more detailed information on the protuberance placements, design, instrumentation and catalytic coating as well as information pertaining only to STS-119 and/or STS-128.

\section{Protuberance Placement}

The protuberance was placed on the port wing of the Orbiter in the same location as the previous flights (see Figure 1). This location was chosen because the port wing had more available instrumentation channels \& wiring. During the planning process it was found that the debris environment on the port side was much more favorable, with a lower incidence of ascent debris related damage as well as more favorable structural and thermal margins in the predicted turbulent wedge. The region of the wing affected by the fully effected turbulent wedge is represented in Figure 1 by the blue wedge.

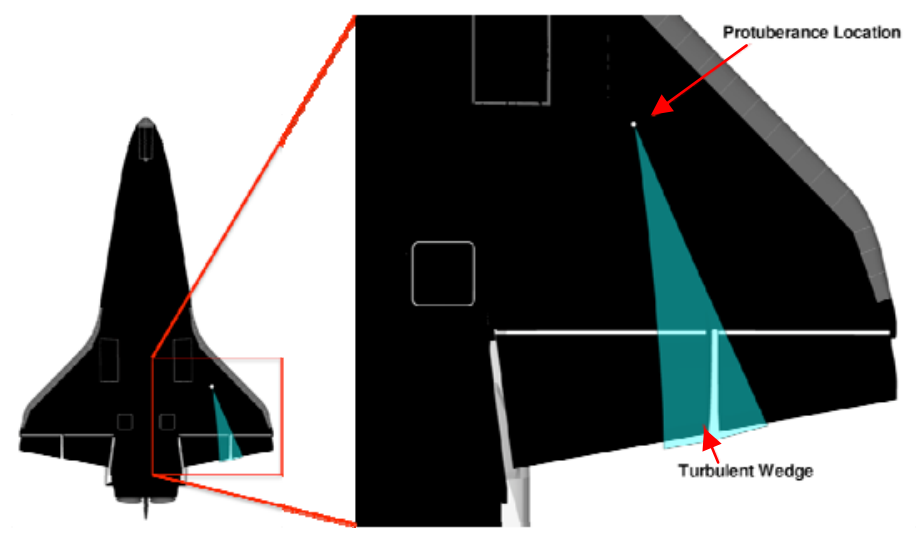

Figure 1: Selected protuberance location and predicted turbulent wedge

\section{Protuberance Design}

An incremental flight envelope expansion approach involving increasing protuberance height has been utilized for the flight experiment. The first flight, STS-119, targeted a BLT onset of approximately Mach 15 in order to be sufficiently above the range of normal vehicle BLT onset that interpretation of the flight data would be easier. The second and third flights on STS-128 and STS-131 targeted approximately Mach 18, with the intent of approaching the earliest flight historical BLT onset Mach numbers, experienced during STS-28 and STS-73. The fourth and fifth flights, STS-133 and STS-134, targeted approximately Mach 19.5, with the intent of exceeding flight experience so that the results would be statistically significant relative to prediction uncertainty. The height of the protuberance was derived using the Orbiter BLT Tool ${ }^{6}$, Version 2 with a $\mathrm{Re}_{\theta} / \mathrm{M}_{\mathrm{e}}$ versus (k/delta)(Hw/Hs) methodology using a best estimate correlation coefficient established from historical Orbiter flight data. The flown protuberance height was 0.25 -in for STS$119,0.35$-in for both STS-128 and STS-131 and 0.5-in for STS-133 and STS-134. As with the first two flights, aerothermal, thermal, and stress analysis was performed for the protuberance, the area immediately surrounding the protuberance, and the downstream regions within and immediately surrounding the turbulent wedge.

A photograph of the final design is shown in Figure 2. The length and width of the protuberance installed on the vehicle were 4.0" and approximately 0.4 ", respectively, for all five flights. The protuberance was machined into the tile such that the leading edge was oriented at 
an angle of $45 \pm 3^{\circ}$ relative to the predicted local flow streamline. This angle and uncertainty were determined graphically using installed hardware pictures that were then scaled onto CFD solutions together with a tile layout. The three-degree uncertainty in the orientation angle comes primarily from the accuracy of angle determination from the combined hardware images and streamline orientation angles, and can be considered a 2-sigma value.

Before and after each flight of the BLT FE, the protuberance and the surface within the predicted turbulent wedge were scanned using Optigo and Metris laser scanning equipment. The purpose of the scanning was to allow for the quantification of any surface changes associated with the re-entry heating, specifically slumping or shape change of the protuberance tile. The 3D scans were performed using the Optigo 200 and Metris Laser Radars. All post flight alignments were done in Geomagic software ${ }^{20}$, using the best fit method. For the first three flights, STS-119, STS-128 and STS-131, the protuberance and catalytic tiles were removed from the vehicle postflight for additional bench scanning and to allow for the installation of the tiles for the next flight. For the last flight of Discovery, STS-133, the tiles were left on the vehicle. This was done because post-flight visual inspections as well as surface scans revealed that there had been no significant shape change and as it was the last flight on Discovery there was no need to prepare the vehicle for additional flights. The current intent is thus that the flight experiment tiles will follow Discovery to her future home and serve as museum articles and testimonies to the success of the Space Shuttle Program.

\section{Catalytic Coated Tiles}

The catalytic coating was applied to two tiles on Discovery for the STS-128 flight and a single tile for the STS-131 and STS-133 flights. For STS-131 and STS-133 the tile was in close proximity to the center of the predicted turbulent wedge, though not in the center. A figure showing the coating applied to the tiles (pre-flight) is shown in Figure 3. A single tile (on the wedge centerline) was coated with the catalytic material for the STS-134 flight of Endeavour. Additional information on the catalytic tiles can be found in references 15 and 21-24.

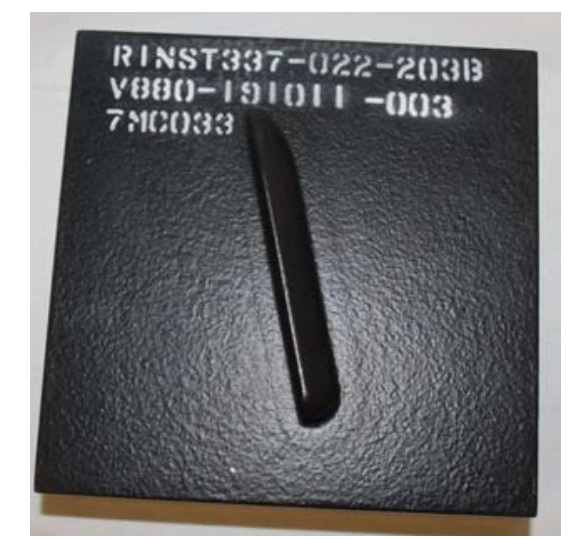

Figure 2: Final protuberance shape

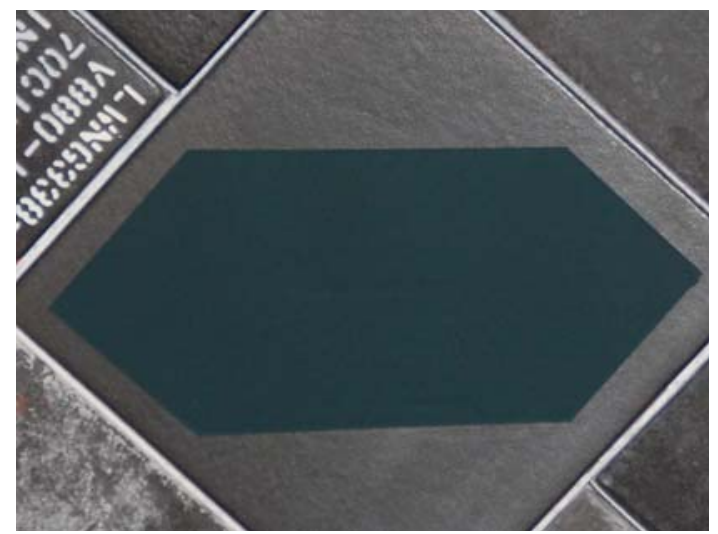

Figure 3: Catalytic Coated Tile on STS-133

\section{Trajectory Design}

As with the previous flights, extensive coordination took place with flight design personnel, flight dynamics officers, and the Ascent-Entry Flight Techniques Panel to communicate potential impacts of Orbiter maneuvers on the flight experiment data. During entry the Orbiter executes a series of roll maneuvers. These roll maneuvers have been hypothesized to affect BLT onset because of the angle of attack and sideslip modulation associated with them. The team established desired 'cut-off' intervals of \pm 1 Mach number on either side of the predicted BLT onset Mach numbers in order to avoid roll reversals during that period of the re-entry. A flight rule related to the flight experiment was established that allows for de-orbit burn modification to occur if the cut-off intervals are violated for the primary entry opportunity on the first day for which an entry is attempted. Within this framework, there was no ability to affect the timing of roll reversals for other landing opportunities beyond the primary landing opportunity defined several days in advance to entry. The Mach number cut-off intervals did affect mission decisions during STS-131. 
Flight Director approval occurred during STS-131 for a retrograde separation and orbit adjustment that pushed the End of Mission (EOM) crossrange outside of the BLT FE crossrange cutout.

In addition to the possibility of the roll maneuvers affecting the time of BLT onset, the first three flights of the BLT FE as well as many previous shuttle missions have experienced a thermocouple anomaly that seems to be associated with the roll maneuver. The anomaly did not affect the time of boundary layer transition but did in many cases make interpretation of the data difficult and resulted in less accurate temperature measurements for certain portions of the trajectory. During the anomaly, the temperature traces exhibit rapid (or in a few cases, slow) shifts up or down at the same time as the roll reversal. This anomaly had a significant effect on STS-128 and as a result the team began to discuss ways to reduce or eliminate the effects. Prior to STS-133, an effort was undertaken to design a re-entry plan that would allow for a delay of all vehicle roll reversals until after Mach 16 . Mach 16 was selected to allow for approximately 100 seconds of higher quality flight data, hopefully unaffected by the temperature anomaly. In order to achieve this, a re-entry trajectory with a large cross-range was necessary which effectively delays the roll reversal to a Mach number lower than 16 due to the manner in which the Orbiter guidance affects roll-reversals for energy management and an accurate approach to the landing location.

A number of ideas were proposed and investigated in order to enable approximately 100 seconds of flight data unaffected by the temperature anomaly. These include

1) Instead of landing at KSC on the first available opportunity, waiting until a trajectory that met the requirements was available. This would have required saving consumables and possibly giving up otherwise viable re-entry opportunities

2) An orbit adjust to try to bring as many trajectories as possible up to the desired crossrange.

3) Opening the first heading error deadband to try to delay the first roll reversal, although depending on the complexity of the change, the lead time may have already been too long for this option. An option to do this manually was also presented, though additional risks were associated with this.

Ultimately it was determined that the best option was to use an orbit adjust to try to extend the cross-range for as many of the re-entry opportunities as possible. A flight rule was written and proposed to the Ascent and Entry Flight Techniques Panel in August 2010. The rule was approved but with the understanding that this was the lowest priority flight rule. It is essential that all other landing constraints would have to be met first, including protecting for adequate landing opportunities, ensuring sufficient consumables remained and that all safety requirements were met.

The first opportunity to utilize the flight rule came during the STS-133 re-entry. Flight Dynamics Officers (FDOs) worked throughout the mission, including the two additional days added to the mission, to determine the requirements necessary to bring the most opportunities to the table that could potentially satisfy the Mach cut-off flight rule. This included the assumption based on predicted stable weather patterns that the shuttle would most likely be able to land on the first day. For this reason, preference was placed on working to satisfy the flight rule for those entry opportunities. The goal was to develop an orbit adjust that would result in as many 3-sigma (preferably) or 1-sigma (second choice) re-entry opportunities with the first roll reversal occurring after Mach 16. Unfortunately the first KSC (KSC 202) entry of the first landing day started with a very small crossrange. This meant that a large retrograde burn (155 fps) would have been required on undocking day in order to at least meet the 1-sigma criteria. The timing and magnitude of the orbit adjust are both important, because the integrated effect on the orbit is cumulative over time. A larger time between the orbit adjust and entry allows for more of an impact on the entry. While possible, it would have been difficult to fit in the timeline and more significantly might have affected the emergency de-orbit capability by eliminating the ability to rerendezvous with the station. This was a significant concern because the burn would have had to have been completed prior to completion of the late TPS inspection and could have prevented rerendezvous with the station in the event of a TPS issue being identified during inspection. Due to these constraints, the decision was made not to execute the new flight rule during STS-133. As a result, the re-entry had a roll reversal at Mach 21.6. 
It should be noted that the higher priority flight rule, protecting against roll reversals during the period \pm 1 Mach number from the expected BLT onset was still in effect and had existed since STS-119. Since the entry trajectories for STS-133 did not nominally violate this flight rule, implementation was not needed for this flight, but would have provided a mechanism in planning the entry trajectory to protect against roll reversals between Mach 20 and 18.

\section{Instrumentation Overview}

Figure 4 shows a sketch of instrumentation locations for STS-119, STS-128, STS-131 and STS-133 (it should be noted that STS-131 and STS-133 are the only two flights to utilize the same instrumentation layouts). White symbols represent instrument locations active for all four flights. Because some of the instruments were not used for all of the flights, instruments that were active for STS-119 only are colored purple, for STS-128 only are colored green and STS-128, STS-131 and STS-133 are colored yellow. The catalytic coated tiles have boxes or triangles surrounding their location which are associated with tiles that were coated for STS-128, STS-131 and STS-133 or STS-128 only, respectively. It is important to note that the flight experiment team was limited to ten active thermocouple measurements because of data acquisition system (DAS) constraints in the wing region. Additional information about the instrumentation system can be found in Reference 16.

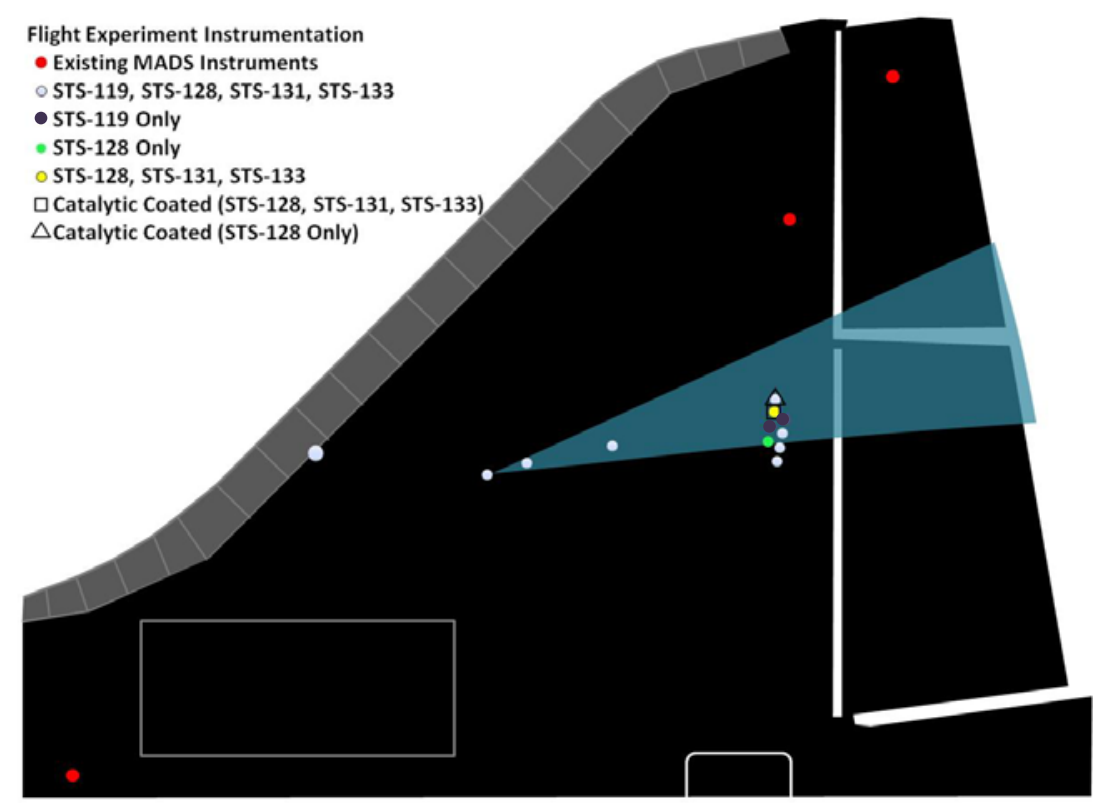

Figure 4: Instrumentation locations for STS-119, STS-128, STS-131 and STS-133.

Since the OV-103/Discovery instrumentation layout had to be designed prior to STS-119, more than ten instrument locations were implemented to facilitate some flexibility in instrument location selection for specific flights. The differences in instrumentation layout between STS-119, STS-128 and STS-131/STS-133 were implemented to (1) obtain higher resolution on the turbulent wedge angle and (2) to take measurements in the two catalytic coated tiles during STS128 and single catalytic tile during STS-131 and STS-133. For STS-131 and STS-133, the single catalytic coated tile contained two thermocouples; one near the beginning and one in the center of the coated region. The thermocouples were placed in this manner to measure the catalytic jump due to a mismatched material ${ }^{25}$ and to measure the general catalytic behavior of the coating, respectively.

For the purposes of comparison to HYTHIRM data and computational predictions, the uncertainty levels associated with the thermocouple measurements were assessed. The components that contribute to the overall uncertainty include a precision uncertainty due to the bit resolution and recording steps in the measurement system, a Modular Auxiliary Data System (MADS) stability precision uncertainty, and a calibration curve precision uncertainty. In 
combination, these precision uncertainties are estimated to be $\pm 20^{\circ} \mathrm{F}$ (1-sigma). In addition to this precision uncertainty, there is also a known bias error due to installation effects. It is estimated that the actual tile surface temperature is approximately $20^{\circ} \mathrm{F}$ hotter than the values reported by the thermocouple measurement due to the thermocouple placement slightly below the actual tile surface. This bias effect is location dependent as each thermocouple is installed at a slightly different depth ${ }^{26}$.

\section{STS-119 Summary}

STS-119 had a 0.25-inch protuberance and a predicted BLT onset of Mach 15.4. Detailed information on the STS-119 flight can be found in reference 15. A post-flight review of the thermocouple data showed a relatively early ( Mach 11.5) asymmetric BLT event on the starboard side of the Orbiter during re-entry, observed in HYTHIRM imagery ${ }^{18,19}$ as shown in Figure 5 (near Mach 9). Thermocouple 1 (hereafter referred to as TC 1), located at the center of the predicted flight experiment wedge, showed the earliest sign of BLT at Mach 15.6. The maximum temperature experienced by any thermocouple was $2012 \operatorname{deg} \mathrm{F}$ and was seen during laminar heating on the protuberance.

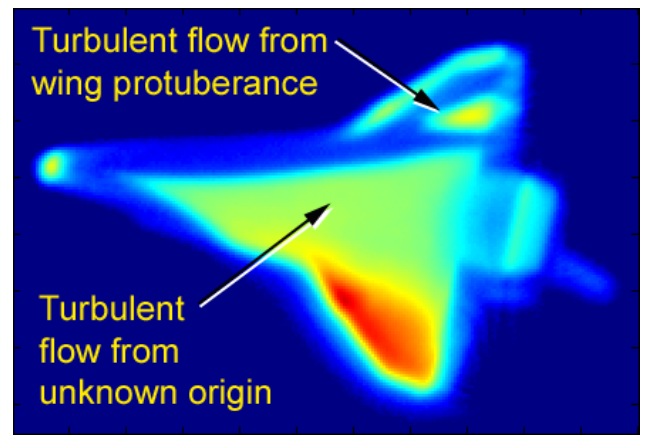

Figure 5: HYTHIRM imagery from STS-119. See References 18, 19

The protuberance tile was removed from the vehicle in a non-destructive manner and was sent to material experts for additional study. It was scanned pre- and post-flight to assess the protuberance shape change and did not change appreciably.

Comparisons between predicted and earliest observed BLT onset times were very favorable (within $\pm 1-\sigma$ ). Comparisons between predicted and observed temperatures were not as favorable and of particular note was the predicted temperature on the protuberance. The pre-flight protuberance temperature prediction was $2892^{\circ} \mathrm{F}$ based on the pre-flight STS-119 trajectory. The maximum reported temperature on the protuberance was $2012^{\circ} \mathrm{F}$. This nearly $900^{\circ} \mathrm{F}$ difference equates to a difference in heat flux of over a factor of four. The cause of the large discrepancy between predicted and observed temperatures is currently unknown. However, hypotheses for the cause of the discrepancy include non-continuum effects ${ }^{27}$, gross errors in the prediction of the boundary layer profile or extent of the separation upstream of the protuberance and errors in the prediction of the thermal response.

\section{STS-128 Summary}

STS-128 had a 0.35-inch protuberance and a predicted BLT onset of Mach 17.4. Detailed information on the STS-128 flight can be found in reference 15. Similar to STS-119, Discovery experienced an early asymmetric BLT event, though this asymmetric event took place upstream of the port wing at approximately Mach 13.6. Figure 6 shows the turbulent wedge for an assumed disturbance location. The effects of this upstream event made it challenging to interpret portions of the flight experiment data as it washed over the protuberance.

TC 1 is located at the center of the predicted flight experiment wedge and shows the earliest sign of non-laminar behavior at Mach 17.5. The maximum temperature from the measurements was just below $2600^{\circ} \mathrm{F}$ and was experienced by the protuberance. At 350 seconds, a number of the flight experiment thermocouples exhibit undesired and erroneous behavior. In retrospect, this behavior has been observed historically on nearly all regions where Orbiter tile surface temperature measurements are made (wing, fuselage, Orbital Maneuvering System (OMS) pod) 
and generally manifests itself as a rapid or gradual decrease or increase in the temperature occurring at the same time as a vehicle roll maneuver.

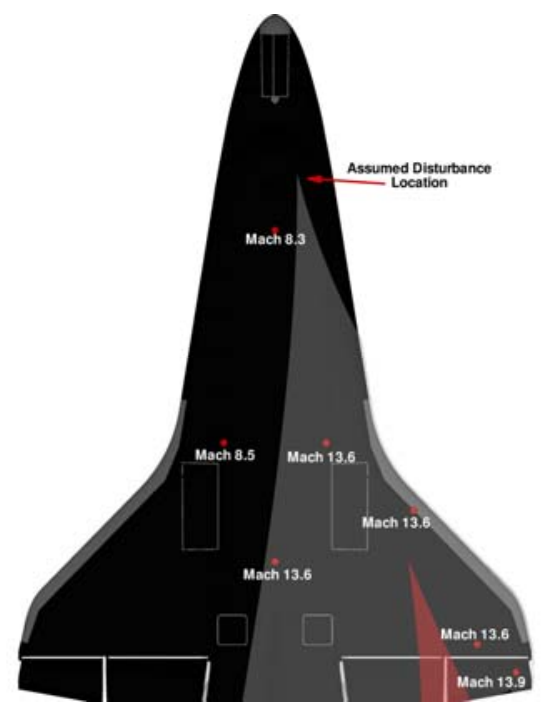

Figure 6: Post-flight reconstruction of asymmetric BLT event.

The protuberance tile was removed from the vehicle post flight in a non-destructive manner. It was scanned prior to and after the mission with Optigo and Metris systems and was scanned again on a bench top using an Optigo optical system to assess the protuberance shape change which was not appreciable.

Comparisons between predicted and the earliest observed BLT onset time was very favorable (within $\pm 1-\sigma$ ). Comparisons between predicted and observed temperatures for STS-128 were better than the comparisons for STS-119; however, the CFD predictions were still higher than actual measurements. This improvement can be attributed to the fact that the STS-128 preflight predictions were adjusted based on the STS-119 flight data.

\section{Analysis in Support of Flight Experiment \#3}

Due to the thermocouple anomaly experienced during STS-128 and the subsequent difficulty in determining peak laminar temperatures on both the protuberance as well as the rest of the tile acreage within the turbulent wedge, the decision was made to re-fly the 0.35 -inch protuberance. Because this was a re-flight of an already analyzed boundary layer trip configuration, significantly less additional analysis and effort was required to achieve program approval for the third flight, STS-131.

\section{STS-131}

\section{Mission Overview}

For STS-131, Space Shuttle Discovery launched from Kennedy Space Center on April 5, 2010. The mission consisted of 3 spacewalks and the Orbiter was docked to the International Space Station (ISS) for 10 days. The three spacewalks consisted of, among many other tasks, installing a new Ammonia Tank Assembly (ATA) and retrieving Micro-Meteoroid Orbital Debris (MMOD) shields. The Orbiter also carried with it the Multi-Purpose Logistics Module (MPLM) Leonardo, which was filled with supplies for the ISS. All prime objectives of the mission were achieved and Discovery landed safely at KSC in Florida on April 20, 2010.

Unlike both STS-119 and STS-128, post-flight examination of thermocouple data showed that boundary layer transition on Discovery was symmetric. The vehicle experienced BLT relatively late in the trajectory, at approximately Mach 6.8. Figure 7 shows the thermocouples and associated BLT Mach numbers on the vehicle. HYTHIRM observations at closest approach were at approximately Mach 15 and are shown in Figure 8. 


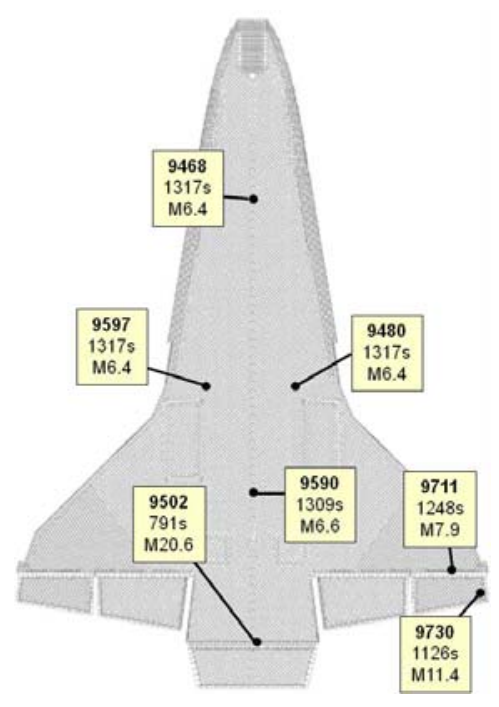

Figure 7: STS-131 flight turbulent heating temperature maximums at BET derived Mach numbers

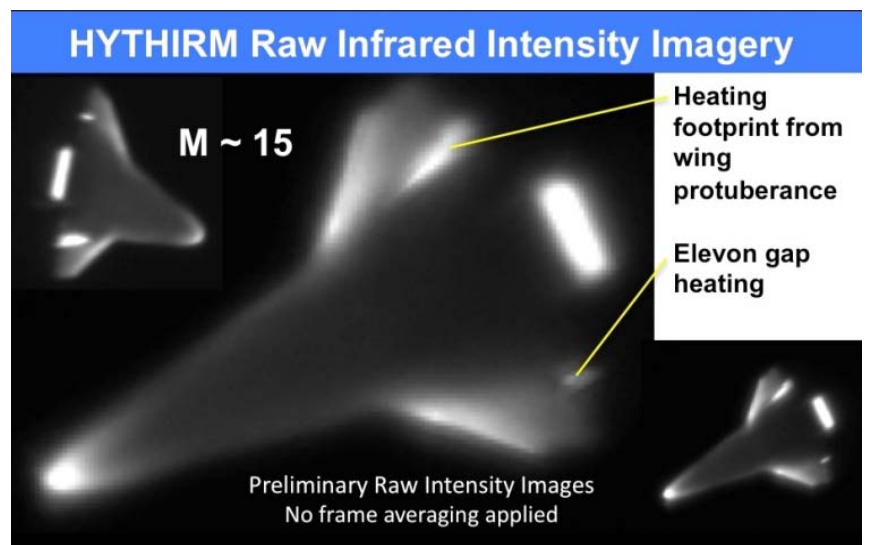

Figure 8: STS-131 HYTHIRM imagery ${ }^{18,19}$

\section{Flight Data Overview}

For convenience during the discussion of the flight data, the labeled flight experiment thermocouples are shown in Figure 9. Thermocouple time traces are shown in Figure 10 and Figure 11 and are plotted in two different figures for the sake of clarity. Figure 10 shows the thermocouple data associated with the flight experiment thermocouples that are furthest aft, while Figure 11 shows the data for thermocouples farther forward and on the protuberance. The data are plotted using the STS-131 post-flight best estimate trajectory (BET).

A quick glance at the aft thermocouple traces in Figure 10 demonstrates that temperatures did not exceed $2000^{\circ} \mathrm{F}$, with the peak temperatures experienced during the turbulent portion of the entry. With the exception of TC 1, TC $3 a$ and TC $3 b$, temperatures during the laminar portion of the trajectory were all similar with peak laminar temperatures between approximately 1500 and $1600^{\circ} \mathrm{F}$. It should be noted again that both TC $3 \mathrm{a}$ and TC 3b had catalytic coating applied to the surface. As such, the elevated temperatures in relation to the other aft thermocouples are expected. It is also worthwhile to note that because of the thermocouple placement at the beginning of the catalytic coating, it was expected that TC $3 \mathrm{~b}$ would exhibit a higher temperature than TC 3a.

TC 1 is located at the center of the predicted wedge and shows the earliest sign of nonlaminar behavior at 929 seconds. This corresponds to a Mach number of 17.4 based on the BET. The thermocouple data then indicates that the transitional wedge progresses inboard, as expected, with TC 3a and 3b (both Mach 15.1, $1012 \mathrm{sec}$ ) showing the next sign of non-laminar behavior, followed by TC 6 (Mach 14.8, $1022 \mathrm{sec}$ ). There appears to be a delay in BLT of approximately 90 seconds between TC 6 and TC 4 (Mach 12.0, $1109 \mathrm{sec}$ ) and another 50 seconds between TC 4 and TC 7 (Mach 10.5, $1157 \mathrm{sec}$ ). Based on this information, it appears that the transitional wedge was initially very narrow before widening later in the trajectory. It should be noted that a number of the thermocouples exhibit the same sudden drop or drifting behavior that was observed in the STS-128 data as well as intermittently in other historical shuttle flight data. The onset of the behavior appears to coincide with initiation of roll reversal maneuvers, including the initial roll from a wings level attitude.

Figure 11 shows the thermocouple traces for the forward and protuberance thermocouples. As is shown, the maximum temperature from the measurements was just below $2200^{\circ} \mathrm{F}$ and was experienced by the protuberance. Examination of the thermocouple traces for these forward instruments shows that all of the forward thermocouples exhibit a drop in temperature at approximately 750 seconds, the same time that a roll reversal maneuver is initiated. TC2 shows 
unexpected behavior at the initiation of roll, approximately 300 seconds after El, when the trace levels out instead of continuing to rise throughout laminar heating as the other traces do.

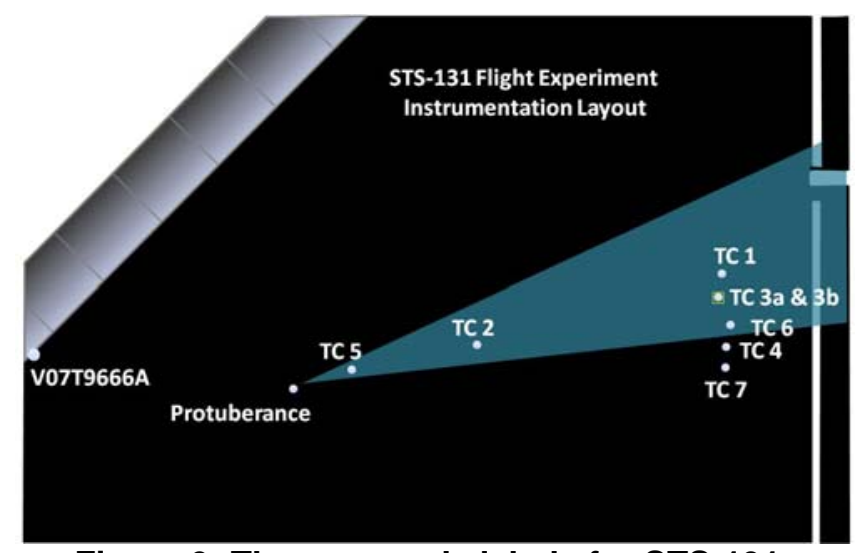

Figure 9: Thermocouple labels for STS-131.

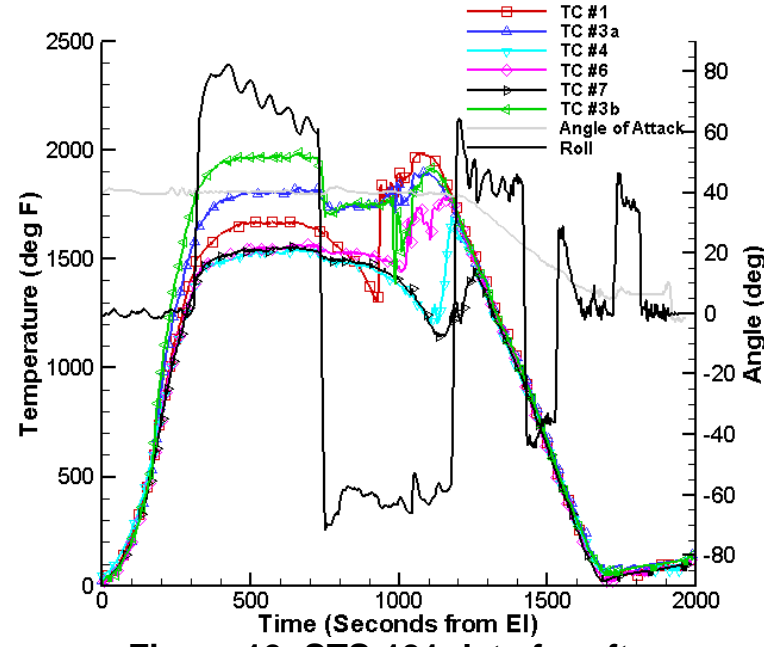

Figure 10: STS-131 data for aft thermocouples

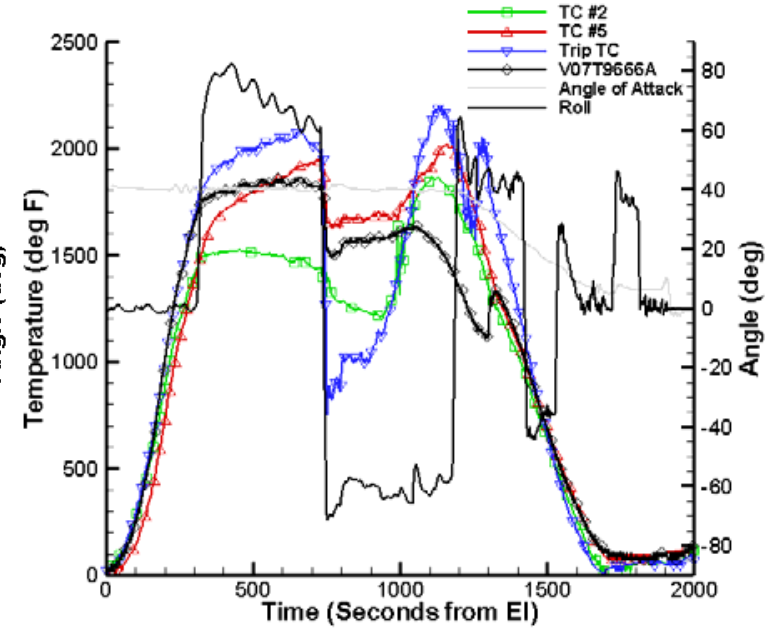

Figure 11: STS-131 data for forward thermocouples

During the early portion of the trajectory it can be seen that the protuberance thermocouple exhibits the highest temperature $\left(2085^{\circ} \mathrm{F}\right)$ and has a laminar peak at approximately 650 seconds. At 750 seconds the temperature then suddenly decreases over $1000{ }^{\circ} \mathrm{F}$ (at the same time as a roll reversal maneuver) before rising again. It then rises to the maximum temperature at around 1115 seconds $\left(2197^{\circ} \mathrm{F}\right)$. Protuberance BLT was assessed to have taken place at 1259 seconds (Mach 7.7). Post-flight visual examination of the protuberance surface by material experts corroborates that the temperature on the protuberance did not exceed $2600{ }^{\circ} \mathrm{F}$ with actual maximum temperatures possibly significantly less.

TC 5, located just aft of the protuberance, experienced a continual rise in temperature over the course of the early portion of the trajectory. This behavior is attributed to the location of the measurement into the vortex-scrubbing region. This vortex heating interaction to the surface masks clear interpretation of the BLT time, although it was estimated at 996 seconds (Mach 15.6).

TC 2 reaches a laminar peak relatively early in the trajectory and then steadily decreases before experiencing a rapid rise in temperature. The rapid rise in temperature is assumed to have been caused by transition from the BLT FE protuberance. V07T9666A seems to exhibit behavior similar to STS-119 and is nominal with the exception of the drop at 750 seconds that all of the flight experiment thermocouples experienced. 
The cause for the measurement anomalies observed on STS-131 is currently unknown, although similar behavior has been seen on previous Orbiter missions, including STS-128 and STS-119. Thermocouple anomaly onset on this flight seems to correlate with the initiation of roll reversals. In this case, the first roll reversal occurred much later than in STS-128 (750 seconds compared to 350 seconds) allowing for significantly more laminar data to be collected. As a result, laminar heating levels are much clearer and offer more confidence than those from STS128. This resulting higher confidence data for the laminar heating levels related to the flight experiment became very helpful in establishing higher confidence flight environment predictions for subsequent missions.

Following the flight of STS-131, tiles downstream of the protuberance were examined by TPS and material experts in a manner similar to STS-119 and STS-128. Based on experience it was determined none of the downstream tiles exceeded a temperature of $2500^{\circ} \mathrm{F}$. This information has proven useful in post-flight reconstruction, and served as an upper bound on the predicted flight temperatures. A runway photograph of the protuberance post-flight is shown in Figure 12. Note the gray 'spotting' that is believed to be due to water exposure on the pad that leads to later aggregation of surface coloring differences.

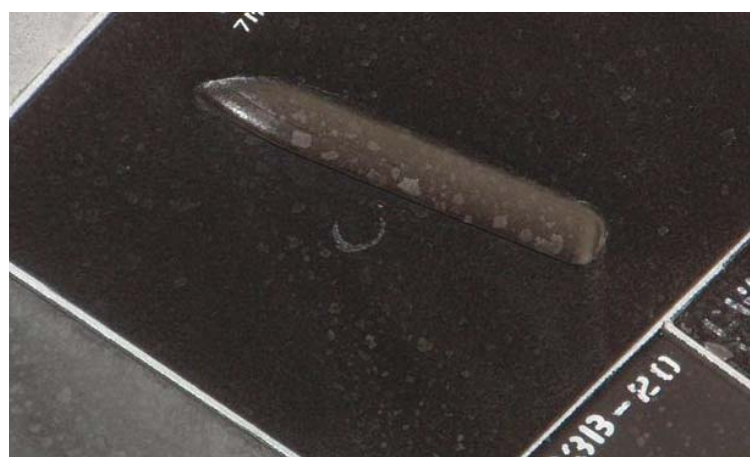

Figure 12: Post-flight runway photograph of STS-131 (0.35-inch) protuberance.

The protuberance tile was removed from the vehicle in a non-destructive manner and was sent to material experts for additional study. The tile was scanned prior to and after the mission with Optigo and Metris systems and was scanned again on a bench top using an Optigo measuring optical system to assess the protuberance shape change. A maximum flattening on the protuberance of 0.01 " was measured (Figure 13). In addition, the catalytic coated tile was removed from the vehicle and replaced with a new LI-900 tile. The catalytic coating seemed to hold up better on STS-131 as compared to STS-128. The forward edge appeared to be fully intact while the aft edge did appear to have some material loss (Figure 14), as noted by the speckled appearance.

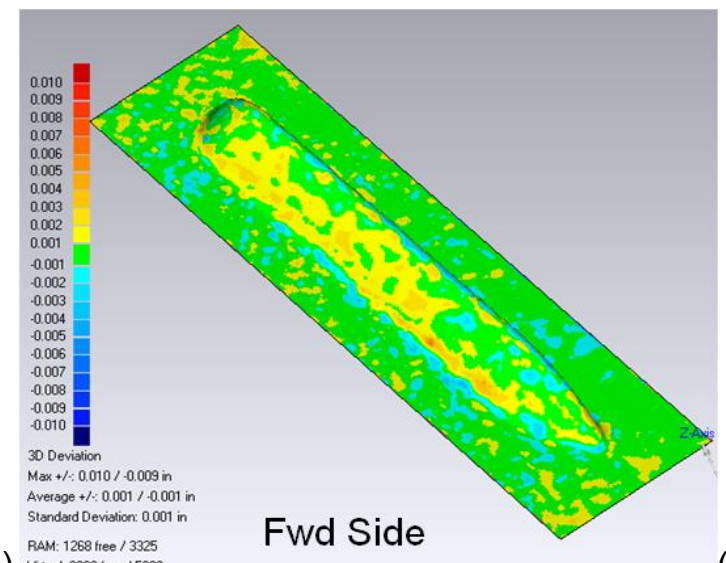

(a) Vim: 1268 tree / 3325

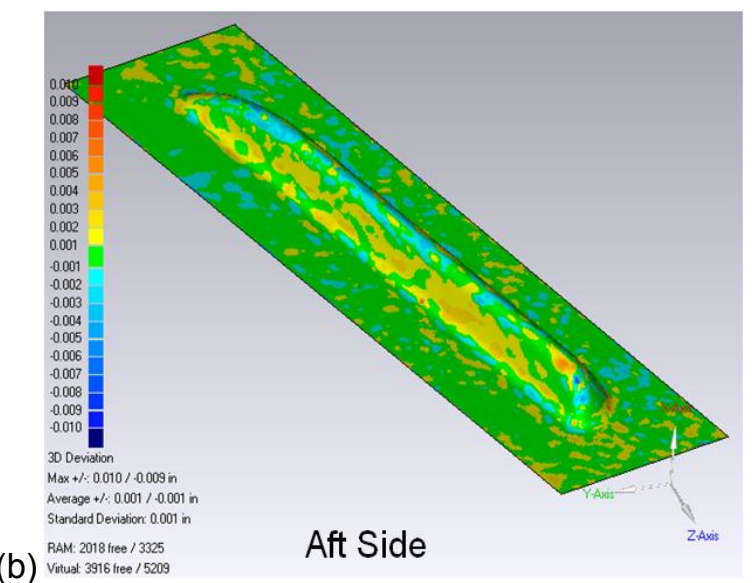

Figure 13: Pre- and post-flight comparison of STS-131 protuberance tile, (a) forward side of protuberance, (b) aft side of protuberance 


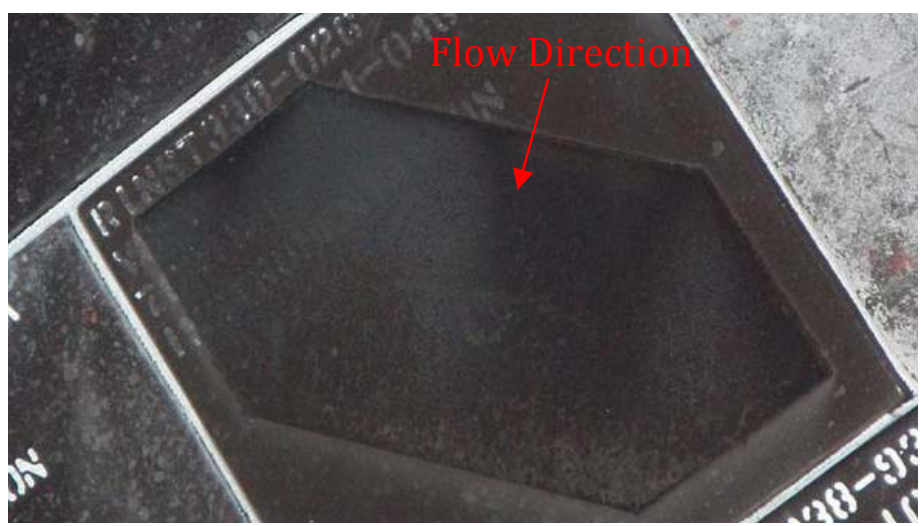

Figure 14: Post-flight runway photograph of catalytic coating following STS-131.

\section{Flight Data and Analysis Prediction Comparisons}

Comparisons between predicted and earliest observed BLT onset times were again very favorable. The predicted onset time for a 0.35-inch height using the BET was Mach 17.2. The observed BLT onset time at TC 1 was Mach 17.4. This is within the $\pm 1-\sigma$ prediction uncertainty of the BLT Tool ${ }^{6}$.

As with the previous flights, the engineering heating environment predictions calibrated with previous flight data lead the thermal math model temperature predictions to be higher than actual measurements. The predicted ISS Heavy Forward (ISSHVFW) certification case and actual temperatures are shown in Table 1. The maximum predicted temperature on the protuberance, based on the ISSHVFW case was $2654^{\circ} \mathrm{F}$, as compared to the maximum-recorded temperature on the protuberance during STS -131 of $2197^{\circ} \mathrm{F}$. Similar to the previous flights, the ability to compare predictions to actual flight data was less precise for the tiles surrounding the protuberance because of the sparseness of the instrumentation. Material expert evaluation led to conclusive statements that the tile coating temperature did not exceed $2500^{\circ} \mathrm{F}$. This is in contrast to the maximum pre-flight prediction of $2995^{\circ} \mathrm{F}$ for the protuberance tile acreage. However, it is believed that the temperatures were actually lower than $2500^{\circ} \mathrm{F}$ and so the over-prediction is more severe than this initial comparison suggests. It is also important to note that the predictions summarized in Table 1 are for a certification case that utilizes a much earlier vehicle BLT time than that experienced on STS-131 (Mach 16.9 in the analysis vs. the actual 7.7 for the protuberance). The time of vehicle BLT is very important because it determines when the protuberance itself will experience turbulent heating. This is separate from the time that BLT occurs downstream of the protuberance, which is primarily affected by the protuberance height.

Table 1: Comparison of Prediction and Flight Temperatures for STS-131

\begin{tabular}{|c|c|c|}
\hline Material & \multicolumn{2}{|c|}{ Peak Temperature ( ${ }^{\circ}$ F) } \\
\hline & ISSHVFW Mach 16.9 & Actual (Trip-Mach 7.7) \\
\hline Protuberance Laminar & 2216 & 2197 \\
\hline Protuberance Turbulent & 2654 & 2053 \\
\hline BRI-18 Laminar & 2518 & $<2500$ \\
\hline BRI-18 Turbulent & 2925 & $<2500$ \\
\hline LI-2200 Laminar & 2471 & $<2500$ \\
\hline LI-2200 Turbulent & 2890 & $<2500$ \\
\hline LI-900 Laminar & 2174 & 1949 \\
\hline LI-900 Turbulent & 2475 & 2022 \\
\hline RTV & 489 & \\
\hline Aluminum & 186 & \\
\hline
\end{tabular}

\section{Analysis in Support of Flight Experiment \#4}

As a result of the additional analysis and the cleaner, though still somewhat compromised, STS-131 flight data, rationale was developed to fly a 0.5 -inch protuberance on the fourth BLT FE flight, STS-133. A similar analysis procedure was used for the fourth flight as was used for the second flight, STS-128, when the protuberance height was increased from 0.25 to 0.35 inches. 
This included the use of a knockdown factor, "k," adjusted for the additional STS- 128 and STS131 data. The factor " $k$ " is the value necessary to match the flight data to the pre-flight predictions, and is then applied to the next higher protuberance height. More information on the knockdown factor can be found in reference 15. Following derivation of knockdown factors from the STS-131 data (0.35-inch protuberance), the results were applied to the STS-133 (0.5-inch protuberance) pre-flight certification analysis. While 0.35 -inch protuberance CFD solutions were used for the STS-131 reconstruction and knockdown factor derivation, 0.50 -inch protuberance CFD heating distributions were used to provide the distribution of heating magnitudes for the STS-133 certification analysis ${ }^{17}$. In this approach, the knockdown factors are applied to the CFD predicted distributions to define the applied engineering calibrated heating predictions.

For the STS-133 certification analysis, the BLT time was derived using a generic ISS return trajectory, a protuberance height of 0.50 -inches, and the $\mathrm{Re}_{\theta} / \mathrm{M}_{\mathrm{e}}$ correlation in the BLT version 2 tool $^{6}$. Results of the analysis are shown in Table 2. For the heating distributions and unadjusted augmentation factor predictions, CFD solutions were available at Mach numbers of 20, 18, 15 , and 12. Linear interpolation was carried out on the values for $k$ and $B F_{C F D}$ for points in the trajectory between the available CFD solutions.

Table 2: STS-133 predictions for ISSHVFW and pre-flight STS-133 trajectories.

\begin{tabular}{|l|c|c|}
\hline \multirow{2}{*}{\multicolumn{1}{|c|}{ Material }} & \multicolumn{2}{c|}{ Peak Temperature ( ${ }^{\circ} \mathrm{F}$ ) } \\
\cline { 2 - 3 } & ISSHVFW M14.6 & STS-133 Mission Specific Trajectory \\
\hline Protuberance & 2944 & 2870 \\
\hline Protuberance tile acreage & 2533 & 2384 \\
\hline LI-2200 tile & 2527 & 2367 \\
\hline LI-900 tile & 2284 & 2216 \\
\hline RTV & 472 & 444 \\
\hline Aluminum structure & 174 & 162 \\
\hline
\end{tabular}

In the case of the ISSHVFW return trajectory (which was used for certification of STS-133), a material temperature waiver was required for the protuberance as the predicted temperature of $2944^{\circ} \mathrm{F}$ exceeded the single-use limit for Boeing Replacement Insulation (BRI)- 18 by $44^{\circ} \mathrm{F}$ for 35 seconds. Rationale for the appropriateness of the waiver was based on the fact that (1) the predicted time of the over-temperature condition was relatively short (2) a certification-level (conservative) trajectory was being used for the assessment and (3) despite the surface overtemperature condition, acceptable tile factors of safety and structural margins were predicted. It was also believed that the analysis was still conservative, even after the adjustments made following STS-119, STS-128 and STS-131. One significant source of conservatism is the vehicle weight. The re-entry weight associated with the ISSHVFW trajectory was approximately 30,000 lbs more than the actual STS-133 re-entry weight.

Because of ground operations schedule constraints, a decision on the plans for the fourth flight experiment (STS-133, originally planned for November 2010, but delayed until February 2011 due to cracks in the stringers on the external tank) was needed relatively soon following STS-131. Analysis was completed within two months and a recommendation from the BLT FE team was accepted by the SSP to fly a 0.50 -in protuberance on STS-133. The catalytic coating was also re-flown. Approval for flight of the highest protuberance height, which would result in BLT onset beyond our historical Orbiter flight experience, required significant discussion with the Crew Office. The last two flights of the BLT FE would not have occurred without intensive coordination between the flight experiment project / technical leadership team, the Orbiter Project, Safety and members of the Program Control Requirements Board (PRCB). This experience demonstrates that flight testing on operational vehicles is still possible. However, future flight testing efforts should be aware that issues only partially motivated by technical issues and more motivated by perceptions need to be addressed in order to be successful. Ultimately, overcoming issues associated with perception need to focus on effectively communicating information and addressing concerns from the perspective of the individuals asking questions. Concurrently with the approval for STS-133, an additional flight, "BLT lite" to be flown on STS-134 (Endeavour), was also approved. STS-134 would utilize the 0.5 -inch protuberance that had been accepted for 
STS-133, the catalytic coating and a reduced set of on-board instrumentation. Details of this flight will be discussed in a later section.

Some weeks after the catalytic coating was applied to Discovery for STS-133 it was noted that the edges of the coating were coming apart from the tile. It was determined that the most likely cause was that the tape used during the spraying process to mask off the surrounding tile area was left on the vehicle too long. Similar to when painters tape is left on a wall too long and may pull up or loosen paint when removed, the tape caused the edges of the coating to loosen. This was an important lesson learned for the program and the situation was remedied by carefully trimming the edges of the coating. After this was completed, the surface was tested with shop air and no additional peeling was noted, nor was it noted in subsequent checks prior to flight.

Because STS-133 was rolled out the launch pad and then back to the Vehicle Assembly Building (VAB) after cracks were found in the external tank stringers, the catalytic coating was continually monitored. After several weeks back in the Vehicle Assembly Building (VAB), a white residue was noted on the surface. Samples were carefully collected and though material testing was, overall, inconclusive there were indications that the residue was most likely due to the launch pad environment and consisted of salt and or sand with only minimal contamination due to the foam associated with the external tank repairs. No further actions were taken prior to flight.

\section{STS-133}

Mission Overview

For STS-133, Space Shuttle Discovery launched from Kennedy Space Center on February 24,2011 . The mission had 2 spacewalks and the Orbiter was docked to the ISS for 10 days. The two spacewalks consisted of, among many other tasks, moving the old ammonia pump and installing power cables linking Unity and Tranquility. The Orbiter also carried with it the Permanent Multi-Purpose Module Leonardo, which was left permanently docked to one of the station's ports, the third Expediting the Process of Experiments to the Space Station (ExPRESS) Logistics Carrier and the humanoid robot, Robonaut. All prime objectives of the mission were achieved. Discovery landed safely at Kennedy Space Center in Florida on March 9, 2011.

Like STS-131, post-flight examination of thermocouple data showed that Discovery had experienced symmetric BLT during the STS-133 re-entry. The BLT was relatively nominal for Discovery, at approximately Mach 8.1. Figure 15 shows the thermocouples and associated BLT BET derived Mach numbers on the vehicle. HYTHIRM observations at closest approach were at approximately Mach 18 and are shown in Figure 16.

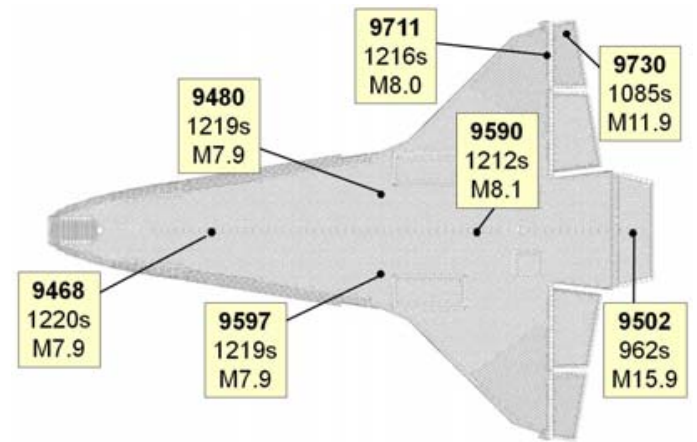

Figure 15: STS-133 flight turbulent heating temperature maximums at BET derived Mach

Flight Data Overview numbers

For convenience during the discussion of the flight data, the labeled flight experiment thermocouples are shown in Figure 17. Thermocouple time traces are shown in Figure 18 and Figure 19. Similar to the STS-131 presentation, the thermocouple data are plotted in two different plots for the sake of clarity. Figure 18 shows the thermocouple data associated with the flight experiment thermocouples that are furthest aft, while Figure 19 shows the data for thermocouples farther forward and on the protuberance. The data is plotted using the post-flight STS-133 BET. 


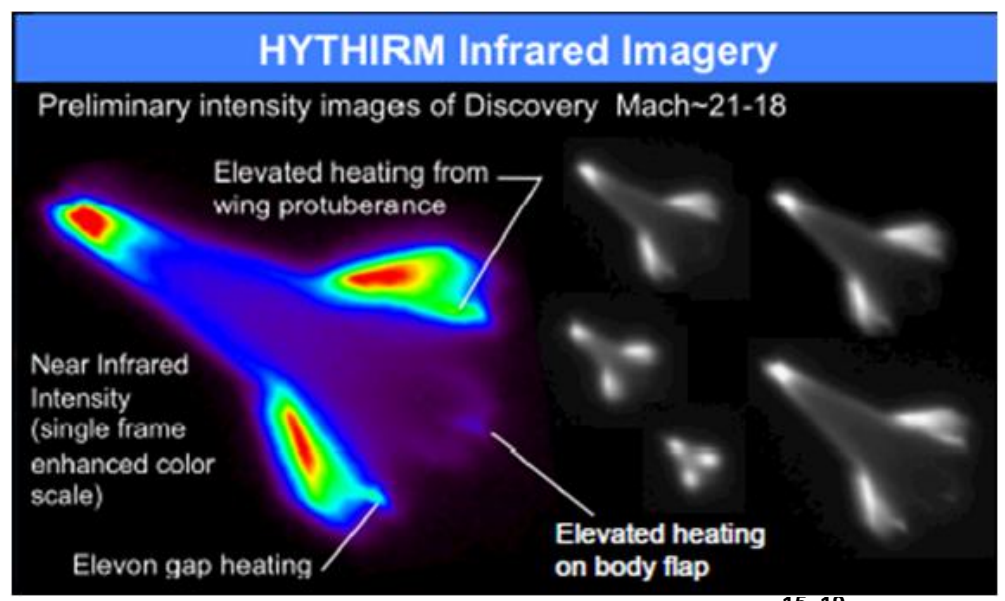

Figure 16: STS-133 HYTHIRM imagery ${ }^{15,19}$

A quick glance at the aft thermocouple traces in Figure 18 shows that temperatures did not exceed $2000^{\circ} \mathrm{F}$, with the peak temperatures experienced during the turbulent portion of the entry. With the exception of TC $3 a$ and TC 3b, temperatures during the laminar portion of the trajectory were all similar with peak laminar temperatures between approximately 1500 and $1600^{\circ} \mathrm{F}$. It should be noted again that both TC $3 a$ and TC $3 b$ locations had catalytic coating applied to the tile surface. As such, the elevated temperatures in relation to the other aft thermocouples are expected. It is also worthwhile to note that because of the thermocouple placement at the beginning of the catalytic coating, it was expected that TC $3 \mathrm{~b}$ would exhibit a higher temperature than TC 3a, with an offset of approximately 130 deg F throughout the laminar region.

TC 1 is located at the center of the predicted wedge and shows the earliest sign of nonlaminar behavior at 725 seconds, corresponding to a Mach number of 21.8 based on the BET. For the next almost 200 seconds the TC 1 thermocouple trace oscillates up and down three full cycles before beginning a final increase at 916 seconds (Mach 17.3). This behavior resulted in four possible indications of boundary layer transition onset, including $725 \mathrm{sec}$ (Mach 21.8), 763 seconds (Mach 21.1), 829 seconds (Mach 19.6) and 916 seconds (Mach 17.3). It is believed that the first two times do not represent boundary layer transition because the same behavior (rapid increase, rapid decrease, followed by a rapid increase) is shown in multiple thermocouples (TC 2, TC 5, 9666, the body flap, the port elevon and the protuberance). This includes a number of thermocouple locations that are not associated with the flight experiment and would not be influenced by the transitional wedge. The behaviors line up with each other within a few DAS cycles (several seconds) in each case. In addition, these events correlate with observed orbiter actions such as a roll reversal, shown to have caused similar behavior on previous flights. As a result, Mach 19.6 and 17.3 remain as possible BLT onset Mach numbers for STS-133. HYTHIRM images collected at approximately Mach 18 indicate that there was a wedge present downstream of the protuberance, indicating that Mach 19.6 is the more likely condition for BLT onset. It is possible that TC 1 may not have been in the center of the transitional wedge at all times and that the wedge, starting very narrow, may have started near Mach 19.6 and then moved off the thermocouple when the vehicle orientation shifted as it does during the re-entry, causing it to appear that the data was re-laminarizing before the wedge moved back over TC 1 at Mach 17.3.

The thermocouple data indicates that the transitional wedge progresses inboard, as expected, with TC 3b and 3a (Mach 17.0, $925 \mathrm{sec}$ and Mach 16.9, $929 \mathrm{sec}$ respectively) showing the next sign of non-laminar behavior, followed by TC 6 (Mach 15.4, $980 \mathrm{sec}$ ), TC 4 (Mach 14.2, $1014 \mathrm{sec}$ ) and then a delay of almost 100 seconds between TC 4 and TC 7 (Mach 11.3, 1106 sec). TC 7 appears to re-laminarize at the same time as the roll reversal at approximately 1140 seconds and then transition again at Mach 9.3 (1168 seconds). This could be explained by the fact that TC 7 is the most inboard thermocouple and thus on the edge of the transitional wedge. The roll reversal caused a change in the vehicle yaw which may have caused the wedge to move slightly outboard and off of TC 7 . At Mach 9.3 the wedge may have expanded enough that it reached TC7 again or the yaw may have shifted back enough to bring the wedge back over TC 7 . 


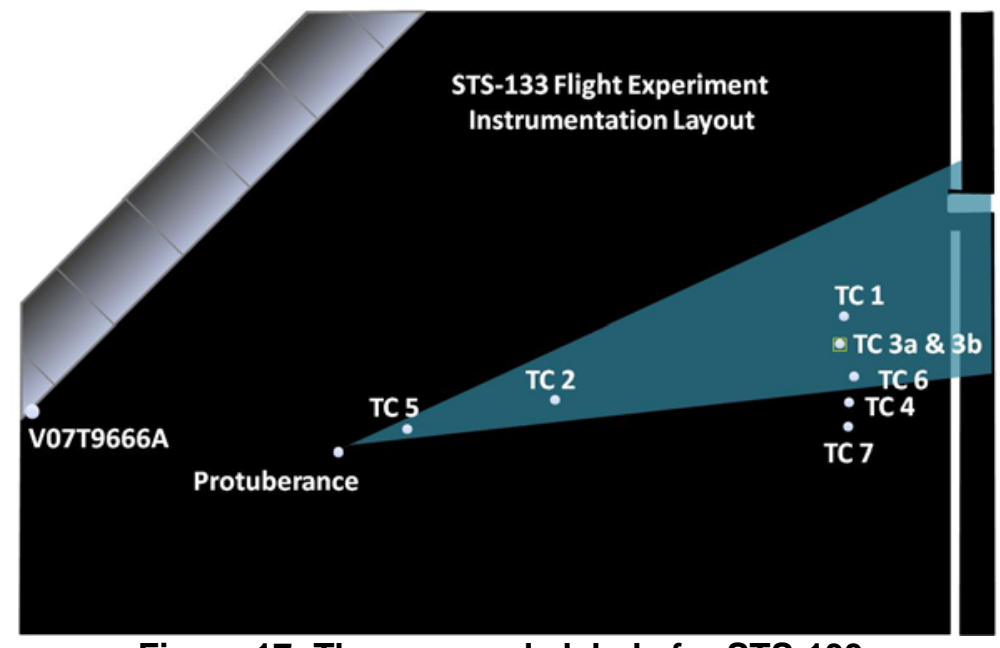

Figure 17: Thermocouple labels for STS-133.

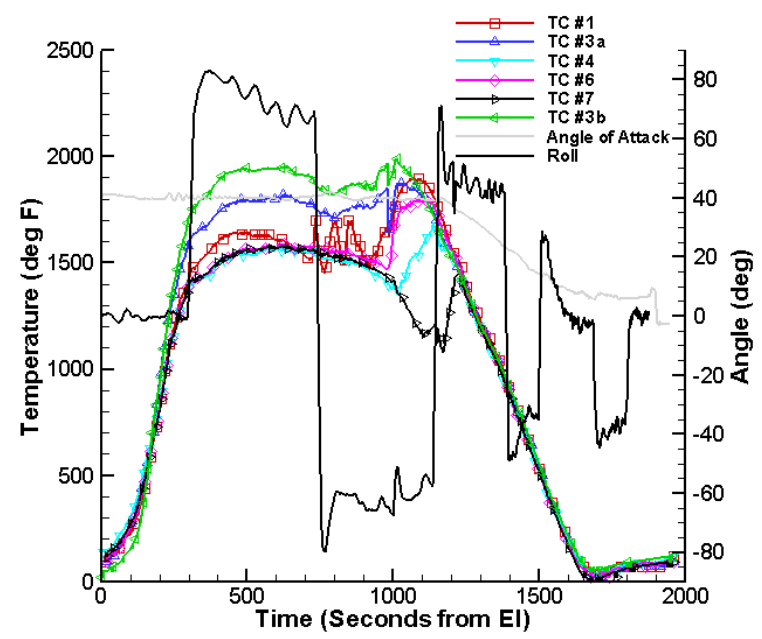

Figure 18: STS-133 data for aft thermocouples

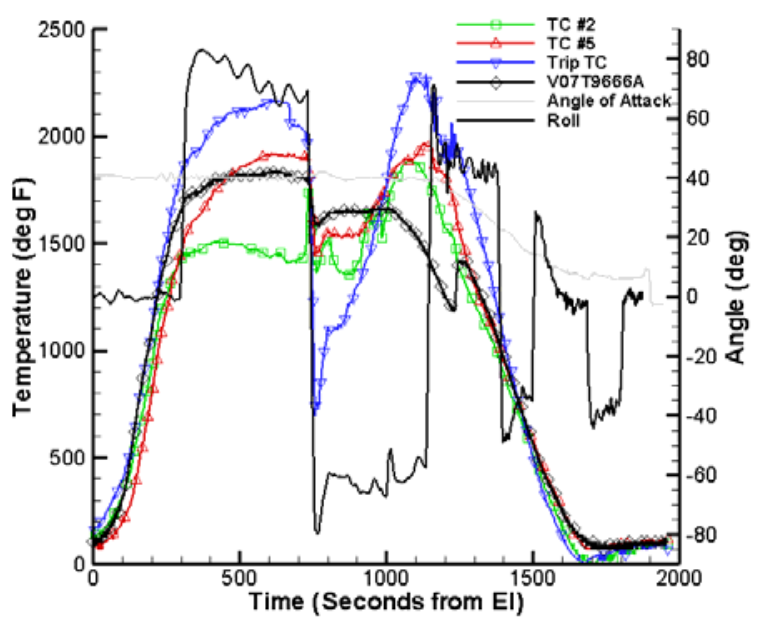

Figure 19: STS-133 data for forward thermocouples

Based on this information, it appears that the transitional wedge was initially very narrow before widening later in the trajectory. It should be noted that a number of the thermocouples exhibit the sudden drop or drifting behavior that was observed in the STS-128 and STS-131 data. The onset of the behavior coincides with initiation of roll reversal maneuvers. Of the aft thermocouples, it appears that TC1, 3a and 3b were the most affected by the anomaly.

Figure 19 shows the thermocouple traces for the forward and protuberance thermocouples. As is shown, the maximum temperature from the measurements was just below $2300^{\circ} \mathrm{F}$ and was experienced by the protuberance under laminar conditions. Examination of the thermocouple traces shows that all of the forward thermocouples exhibit a drop in temperature at approximately 750 seconds, the same time that a roll reversal maneuver is initiated.

During the early portion of the trajectory it can be seen that the protuberance thermocouple reached a maximum laminar temperature of 2166 degrees $F$ at approximately 650 seconds. At 750 seconds the temperature then suddenly decreases over $1300^{\circ} \mathrm{F}$ in 40 seconds (at the same time as a roll reversal maneuver) before beginning to rise again. The thermocouple trace is very similar to STS-131, which also experienced a roll reversal at about 750 seconds. It then rises to the maximum temperature at approximately 1100 seconds (2288 deg). It should be noted that this is still in the laminar heating regime. Protuberance BLT was assessed to have taken place at 1204 seconds (Mach 8.3). Post-flight visual examination of the protuberance surface by material experts corroborates that the temperature on the protuberance did not exceed $2600^{\circ} \mathrm{F}$. 
TC 5, located just aft of the protuberance, experienced a rise in temperature over the course of the early portion of the trajectory. This behavior is attributed to the measurement intentionally being placed within the vortex-scrubbing region caused by the streamwise vortex that originates at the protuberance trailing edge. This vortex heating as well as the thermocouple-anomalyinduced drop in the temperature at 750 seconds complicates any clear interpretation of the BLT time, although the data support estimates at either 906 seconds (Mach 17.6) or 1087 seconds (Mach 11.9).

TC 2 effectively stops rising at the first onset of vehicle roll at about 300 seconds. Just prior to the first roll reversal the thermocouple indicates a sharp rise and then drop in the temperature, similar to the behavior of TC 1 . This occurs at the same time as a change in the vehicle yaw and may indicate that the vortex is briefly rolling over the thermocouple before the vehicle roll stabilizes again. This makes the determination of the maximum laminar temperature of TC 2 very difficult. BLT onset for TC 2 is believed to have occurred at either 888 seconds (Mach 18.1) or 953 seconds (Mach 16.2). V07T9666A seems to exhibit expected behavior with the exception of the drop at 750 seconds that a number of the thermocouples experienced. BLT appears to have occurred at 1232 seconds (Mach 7.6), roughly at the same time as the remainder of the orbiter acreage experienced BLT, and relatively nominally for OV-103.

Anomaly onset on this flight seems to correlate with the initiation of roll reversals, as with the previous flights. During STS-133, the first roll reversal occurred at approximately the same time as it occurred on STS-131 and much later than in STS-128 (750 seconds compared to 350 seconds).

Following the flight of STS-133, tiles downstream of the protuberance were examined by TPS and material experts. According to the runway report, the BLT protrusion was in good condition, with some glazing on the tip. A runway photograph of the protuberance is shown in Figure 20 and the catalytic coating tile is shown in Figure 21 . The catalytic coating was missing some coating from the forward outboard edge of its footprint. It was noted earlier that the catalytic coating did have issues with peeling pre-flight and this may explain some of the missing coating on the edges. Based on experience it was determined none of the downstream tiles exceeded a temperature of $2500^{\circ} \mathrm{F}$.

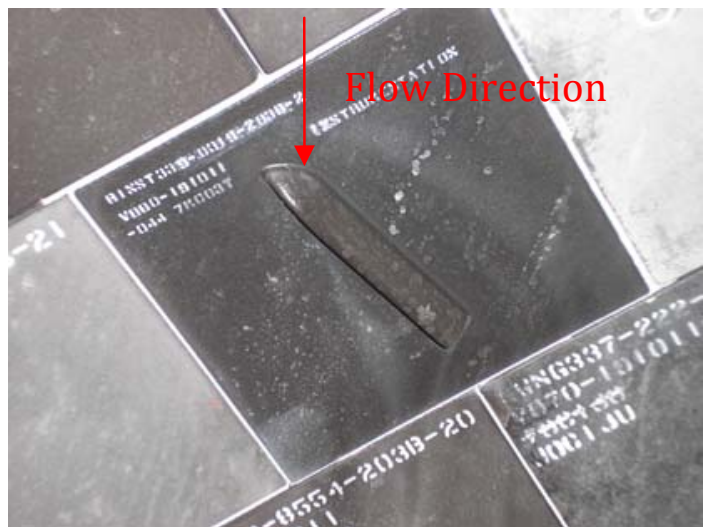

Figure 20: Post-flight runway photograph of STS-133 (0.50-inch) protuberance.

Because this was the final flight of OV-103 (Discovery) and the tiles were in good overall condition, the decision was made not to remove either of the tiles. The tiles were scanned prior to and after the mission with Optigo and Metris systems to assess the protuberance shape change. A maximum deviation on the protuberance of 0.006 inches was measured (with a standard deviation of 0.001 inches for the resulting digital surface definition). Images of the protuberance tile changes between pre- and post-flight measurements are shown in Figure 22. Overall the catalytic coating seemed to hold up well, with the exception of the material loss at the forward edge of the coating.

Flight Data and Analysis Prediction Comparisons

Comparisons between predicted and earliest observed BLT were difficult on this flight due to the uncertainty in the actual BLT onset Mach number associated with TC1. This difficulty is 
primarily due to occurrence of the thermocouple anomaly. The predicted onset time for a $0.50-$ inch height using the STS-133 EOM mission specific trajectory was Mach 19.2. The observed BLT onset time at TC 1 was believed to have been Mach 19.6.

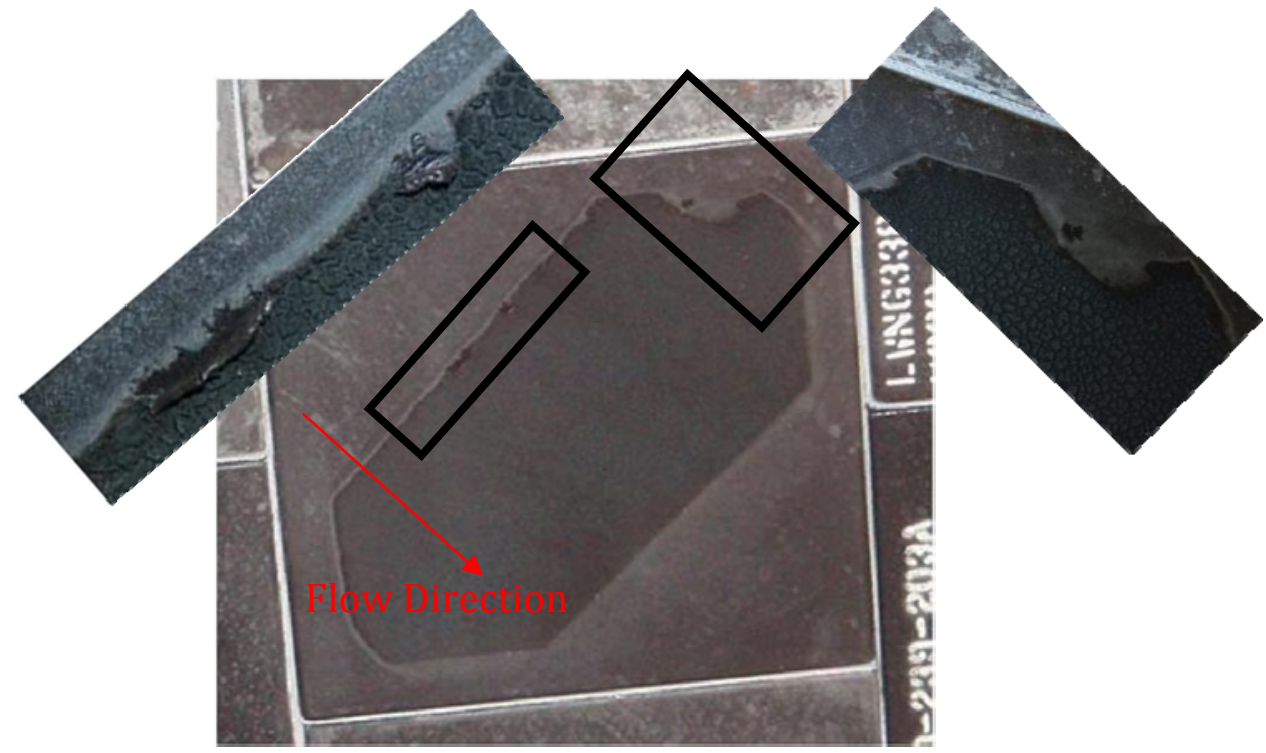

Figure 21: Post-flight runway photograph of catalytic coating following STS-133.

(a)

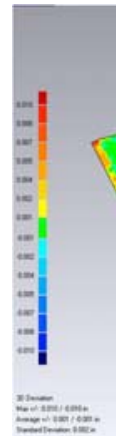

(a)

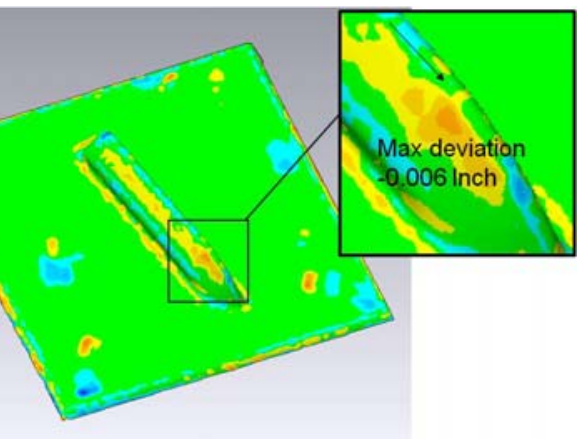

(b)

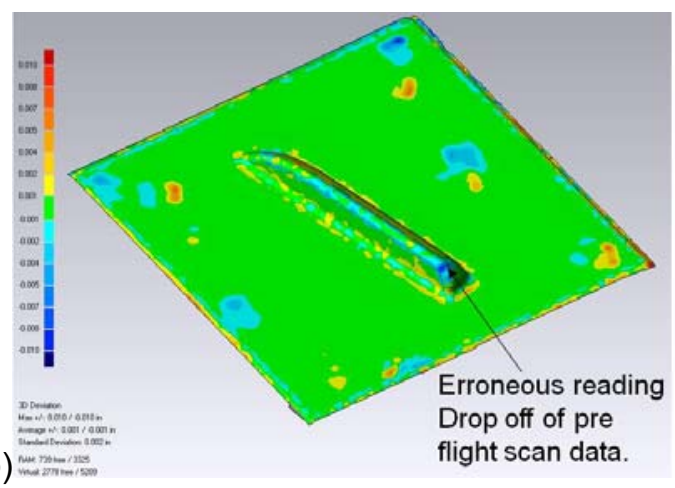

Figure 22: Pre- and post-flight comparison of STS-133 protuberance tile, (a) forward side of protuberance, (b) aft side of protuberance

As with the previous flights, the engineering predictions for temperature were found to be higher than actual measurements. Predicted temperatures on the protuberance were $2870^{\circ} \mathrm{F}$ (based on the STS-133 mission specific trajectory), as compared to the maximum-recorded temperature on the protuberance of $2288^{\circ} \mathrm{F}$. It is important to note however that the mission specific trajectory assumes that the protuberance transitioned at Mach 13.2, where the actual $\mathrm{BLT}$ onset was closer to Mach 8.3. The turbulent temperature at Mach 8.3 on the prediction was $2310^{\circ} \mathrm{F}$, much closer to the measured flight temperature. Similar to the previous flights, the ability to compare predictions to actual flight data was less precise for the tiles surrounding the protuberance because of the sparseness of the instrumentation. Material experts have conclusively stated that the tile coating temperature did not exceed $2500^{\circ} \mathrm{F}$; however, it is believed that the temperatures were actually lower than $2500^{\circ} \mathrm{F}$. The maximum pre-flight prediction for the protuberance tile acreage was $2384^{\circ} \mathrm{F}$. The maximum measured temperature on the LI-900 tile acreage was $1991^{\circ} \mathrm{F}$ as compared to the maximum predicted temperature of $2216^{\circ} \mathrm{F}$ (both of them corresponding to turbulent conditions).

The predictions, including the certification case and the mission specific EOM cases, as well as the actual temperatures measured are shown in Table 3 . It is important to note that the different sets of information each assume different boundary layer transition onset (for the 
protuberance) and predictions assume earlier transition than was experienced. An important take away from the comparison is that all measured temperatures were below those predicted in the mission specific or certification trajectories. Those areas that did not have instrumentation did not show any signs that they would have exceeded the predicted temperatures.

Table 3: Comparison of Prediction and Flight Temperatures for STS-133

\begin{tabular}{|c|c|c|c|}
\hline Material & \multicolumn{3}{|c|}{ Peak Temperature ( ${ }^{\circ}$ F) } \\
\hline & $\begin{array}{c}\text { ISSHVFW } \\
\text { (Mach 14.6) }\end{array}$ & $\begin{array}{c}\text { Mission Specific } \\
\text { (Mach 13.2) }\end{array}$ & $\begin{array}{c}\text { Actual } \\
\text { (Trip Mach 8.3) }\end{array}$ \\
\hline Protuberance Laminar & 2445 & 2376 & 2288 \\
\hline Protuberance Turbulent & 2944 & 2870 & 2064 \\
\hline BRI-18 Laminar & 2439 & 2384 & $<2500$ \\
\hline BRI-18 Turbulent & 2533 & 2351 & $<2500$ \\
\hline LI-2200 Laminar & 2413 & 2367 & $<2500$ \\
\hline LI-2200 Turbulent & 2527 & 2319 & $<2500$ \\
\hline LI-900 Laminar & 2166 & 2113 & 1960 \\
\hline LI-900 Turbulent & 2284 & 2216 & 1991 \\
\hline RTV & 472 & 444 & \\
\hline Aluminum & 174 & 162 & \\
\hline
\end{tabular}

Analysis in Support of Flight Experiments \#5

Prior to the STS-133 flight, and during the time in which the STS-133 flight was being approved for the 0.5 " protuberance, a proposal to execute a scaled back version of the flight experiment (including the boundary layer trip and four thermocouples) was approved for STS134, to be flown on OV-105/Endeavour. It was decided that the protuberance would be the same height as STS-133, 0.5", due to the rapid turnaround time required by the flight manifest as well as to allow the team to collect repeat data on a different vehicle. Included in the technical rationale for an additional flight was that addition of a fifth flight would allow the uncertainty in the mean conditions for BLT onset to approach a magnitude approximately equal to or less than the 1-sigma prediction uncertainty. Because the same protuberance height would be flown on STS134 as STS-133, pre-flight analysis was much less involved and much of the STS-133 analysis was used for the STS-134 flight certification (the vehicles had very similar entry weights).

\section{Instrumentation Configuration for OV-105}

As previously stated, the fifth and final flight of the BLT FE was on OV-105 (Endeavour), representing the first flight on that vehicle. Each orbiter has a unique thermocouple layout and while OV-103 only had six thermocouples prior to the flight experiment additions, OV-105 had fourteen (Figure 23). Due to time constraints and limitations on available channels, only four additional thermocouples were added to the vehicle in preparation for the flight. It should be noted that OV-105 was already equipped with the "control" thermocouple on the port wing (V07T9666A) so it was not necessary to add additional instrumentation in that region to match OV-103. Key differences between STS-133 and STS-134 flight experiments include:

- Two thermocouples are wired with a different configuration (S-turn), allowing the team to examine the effects of the wiring on the thermocouple anomaly. The belief is that the S-turn layout will decrease the cross-sectional area defined by the wire runs in the tile. Bench top evaluations of the antenna power of a typical thermocouple layout can decrease the radio frequency (RF) reception magnitude in the $1-3 \mathrm{GHz}$ range by several decades. It is hypothesized that this change may reduce or eliminate the previously observed thermocouple anomaly if it is due to RF interactions. This belief is motivated by the perspective that the nominal wiring layout in a silica tile creates a geometric configuration much like a UHF antenna. A diagram of the protuberance and "Trip 2" (the S-turn) thermocouples is shown in Figure 24.

- The thermocouples will be routed through the thermocouple reference junction (TRJ) and then a strain gage signal conditioner before going to the MADS pulse code modulation (PCM) unit. The control TC 9666 was already present on the vehicle and will be routed through the normal TRJ directly to MADS PCM only. This mitigation will attempt to reduce 
the potential for external flow field effects causing a bias in the ground plane voltage that may affect the flight experiment thermocouple measurements.

A diagram of the thermocouple locations is shown in Figure 25. Figure 26 shows pre-flight images for all thermocouples except for TC \#1. The four thermocouples utilized for STS-134 are:

- Trip \#1: on the protuberance in the same location as on OV-103.

- Trip \#2: on protuberance tile but not on protuberance or in the vortex region and has the Sturn layout.

- TC \#5: same location as on OV-103 and has the S-turn configuration as well as an exposed thermocouple junction.

- TC \#1: located in the same location as on OV-103 and has catalytic coating.
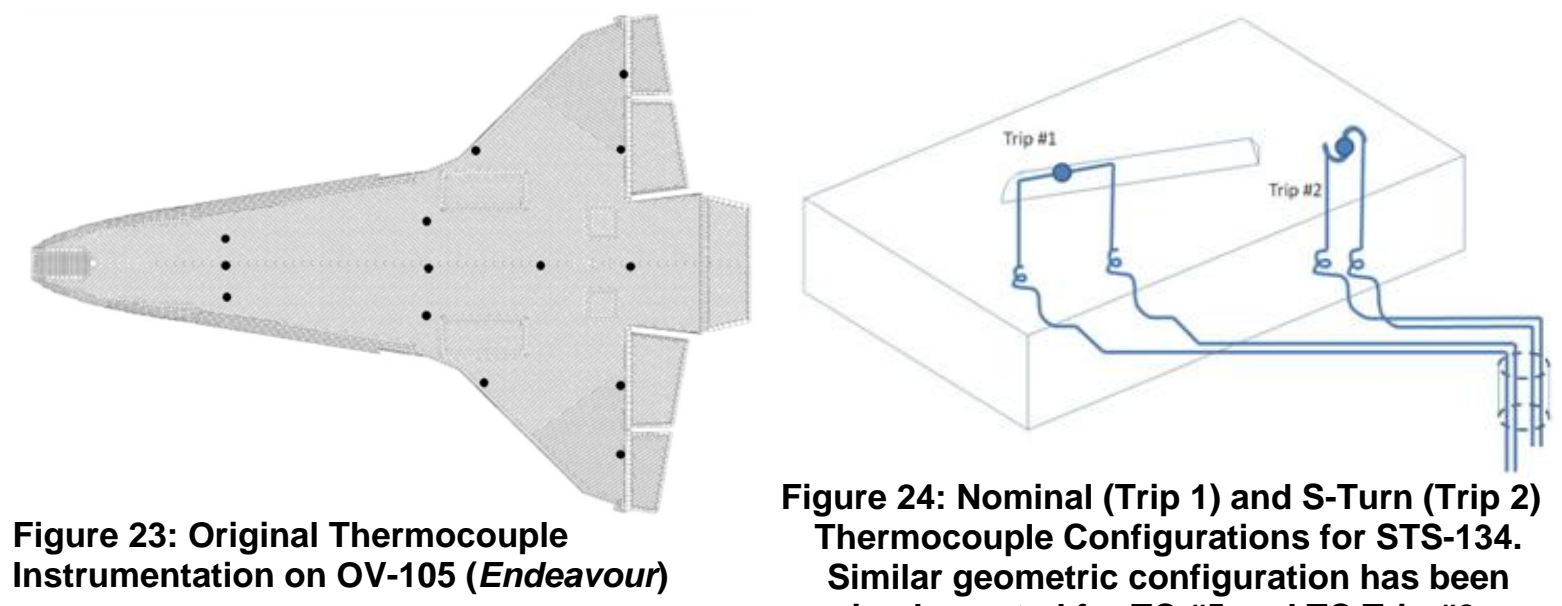

Figure 24: Nominal (Trip 1) and S-Turn (Trip 2) Thermocouple Configurations for STS-134.

Similar geometric configuration has been implemented for TC \#5 and TC Trip \#2.

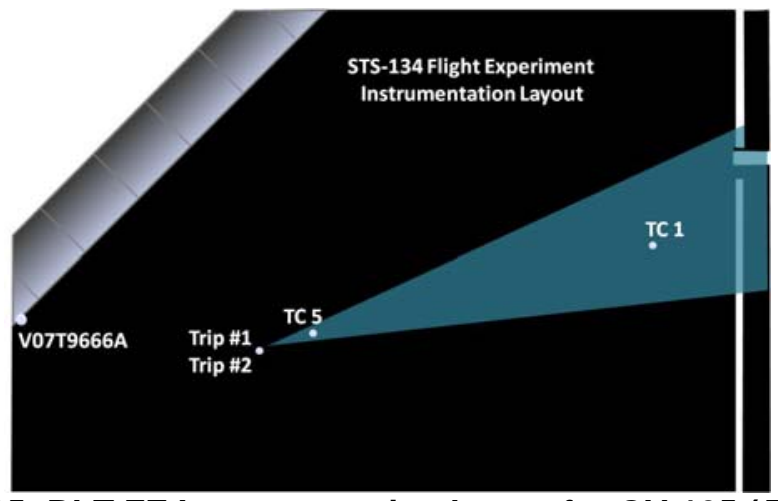

Figure 25: BLT FE Instrumentation layout for OV-105 (Endeavour)

(a)

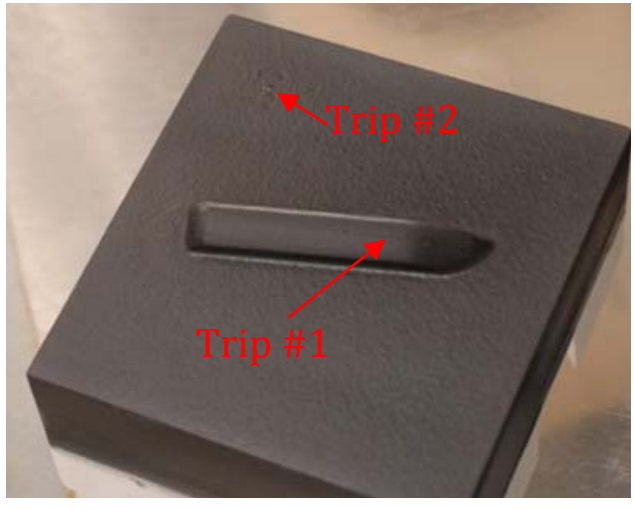

(b)

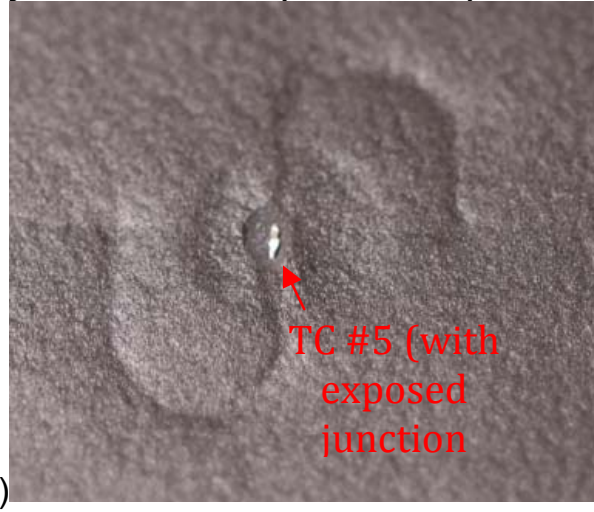

Figure 26: Pre-Flight Installation Images of Special Thermocouples Installed for OV-105. (a) Trip \#1 and Trip \#2; (b) TC \#5

American Institute of Aeronautics and Astronautics 
In addition to changes to the vehicle instrumentation, a series of the LI-900 tiles immediately downstream of the protuberance tile were replaced with LI-2200 tiles. Four tiles on OV-105 were replaced, an implementation analogous to that on OV-103 that is performed in order to have tiles immediately downstream of the protuberance which have a higher single use temperature capability. Just as with OV-103, the protuberance tile was fabricated out of BRI-18. A diagram of the tiles altered is shown in Figure 27.

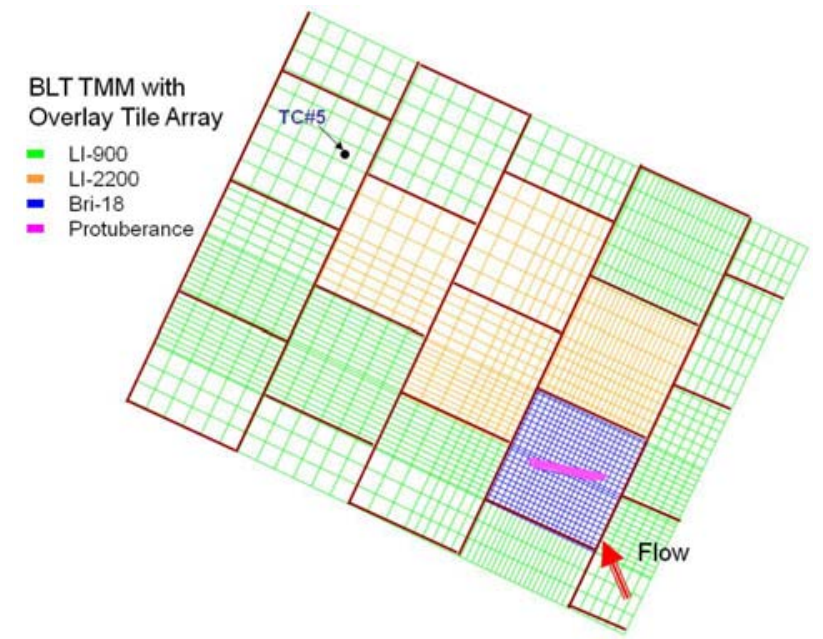

Figure 27: Tile materials used in the vicinity of the protuberance tile for OV-105

\section{Conclusions and Summary}

In support of the Boundary Layer Transition Flight Experiment Project, a manufactured protuberance tile was installed on the port wing of Discovery and flown on STS-119, STS-128, STS-131 and STS-133 as well as Endeavour for STS-134. Additional instrumentation was installed in order to obtain more spatially resolved measurements downstream of the protuberance. This instrumentation measured boundary layer transition and associated temperatures during flight. Comparisons of temperature predictions and the obtained flight data have shown that while BLT onset times have been accurately predicted using the engineering correlations, CFD based heating predictions are significantly higher than measured temperatures on the protuberance and in the region close to the protuberance. The reason for these discrepancies is currently unknown. Additionally, a thermocouple anomaly resulting in rapid or gradual shifting of temperatures has been observed for all of the BLT FE flights and seems to correlate to when the vehicle executes roll reversal maneuvers. This temperature measurement anomaly has made interpretation of the flight data difficult. Although the cause of the anomaly is unknown, steps have been taken on the fifth and final flight on STS-134, to mitigate the anomaly. Modified thermocouples were installed on Endeavor and an attempt will be made to alter the re-entry trajectory to offer more favorable conditions.

\section{References}

1. Campbell, C.H., Anderson, B.P., King, R.A., Kegerise, M.A., Berry, S.A., Horvath, T.J., "Roles of Engineering Correlations in Hypersonic Entry Boundary Layer Transition Prediction," AIAA 2010-247, January 2010.

2. Berry, S.A., Bouslog, S.A., Brauckmann, G.J., Caram, J.M., "Shuttle Orbiter Experimental BoundaryLayer Transition Results with Isolated Roughness", Journal of Spacecraft and Rockets, Vol. 35, No.3, 1998, pp. 241-248.

3. Berry, S.A, Horvath, T.J., Greene, F., Kinder, G.R., Wang, K.C., "Overview of Boundary Layer Transition Research in Support of Orbiter Return to Flight", AIAA 2006-2918, June 2006.

4. Berry, S., A., Hamilton, H., "Discrete Roughness Effects on Shuttle Orbiter at Mach 6", AIAA 20022744, June 2002.

5. Campbell, C.H., Garske, M.T., Kinder, G., Berry, S.A., "Orbiter Entry Boundary Layer Flight Testing", AIAA 2008-635, January 2008. 
6. Berry, S.A., King. R.A., Kegerise, M.A., Wood, W., McGinley, C., Berger, K., Anderson, B.P., "Updates to Orbiter Boundary Layer Transition Prediction Tool," AIAA 2010-246, January 2010.

7. Campbell, C.H., et. al., "Orbiter Return to Flight Entry Aeroheating", AIAA 2006-2917, June 2006.

8. Hyatt, A.J., Wang, K.C., Everhart, J.L., Green, F., Merski, N.R., Wood, W.A., Berger, K., Anderson, B.P., Cassady, A., "The Cavity Heating Tool: Version 3.0 Documentation", Boeing Technical Memorandum, ATA-AH-TM-2006-035, Houston, TX, 2006.

9. Everhart, J. L., Greene., F. A., "Turbulent Supersonic/Hypersonic Heating Correlations for Open and Closed Cavities," Journal of Spacecraft and Rockets, Vol. 47, No. 4, 2010, pp. 545-553.

10. Everhart, J. L., "Supersonic/Hypersonic Laminar Heating Correlations for Rectangular and Impact Induced Open and Closed Cavities," Journal of Spacecraft and Rockets, Vol. 46, No. 3, 2009, pp. 545-560.

11. Tang, C., Saunders, D., Trumble, K., Driver, D., "Rapid Aerothermal Simulations of Damage and Repair During a Space Shuttle Mission", AIAA 2007-1783, April 2007.

12. Palmer, G., Pulsonetti, M., Wood, W., Alter, S., Gnoffo, P., Tang, C., "Computational Assessment of Thermal Protection System Damage Experienced During STS-118", Journal of Spacecraft and Rockets, Vol. 46, No. 6, 2009, pp. 1110-1116.

13. Berry, S.A., Horvath, T.J., Cassady, A.M., Kirk, B.S., Wang, K.C., Hyatt, A.J., "Boundary Layer Transition Results from STS-114", AIAA 2006-2922, June 2006.

14. Bertin, J.J., Schneider, S.P., Campbell, C.H., "A Flight-Testing Proposal on Roughness-Induced Boundary-Layer Transition on the Space Shuttle Orbiter", NASA White Paper, November 14, 2006.

15. Anderson, B. P., Campbell, C. H., Saucedo, L. A., Kinder, G. R., Berger, K. T., "Boundary Layer Transition Flight Experiment Overview and In-Situ Measurements," AIAA 2010-0240, January 2010.

16. Spanos, T., Kinder, G., Campbell, C.H., Andress, J., "Boundary Layer Transition Flight Experiment Thermal Protection System and Instrumentation Modifications", AIAA 2010-242, January 2010.

17. Tang, C., Wood, W.A., "Numerical Simulations of the Boundary Layer Transition Flight Experiment", AIAA 2010-453, January 2010.

18. Horvath, T.J., Tomek, D.M., Berger, K.A., Zalameda, J.N., Splinter, S.C., Krasa, P.W., Schwartz, R.J., Gibson, D.M., Tietjen, A.B., Tack, S., "The HYTHIRM Project: Flight Thermography of the Space Shuttle during Hypersonic Flight", AIAA 2010-241, January 2010.

19. Spisz, T. S., Taylor, J. C., Gibson, D. M., Horvath, T. J., Zalameda, J. N., Tomek, D. M., Tietjen, A. B., Tack, S., and Bush, B., "Processing Near-Infrared Imagery of Hypersonic Space Shuttle Reentries," Thermosense XXXII Conference at the SPIE Symposium on Defense, Security, and Sensing, SPIE Paper 7661-17, April 2010.

20. See http://www.geomagic.com/en/

21. Rakich, J.V., Stewart, D.A., Lanfranco, M.J., "Results of a Flight Experiment on the Catalytic Efficiency of the Space Shuttle Heat Shield", AIAA-1982-944, June 1982.

22. Stewart, D. A., Rakich, J. V., and Lanfranco, M. J., "Catalytic Surface Effects Experiment on the Space Shuttle," Progress in Astronautics and Aeronautics: Thermophysics of Atmospheric Entry, Vol. 82, edited by T. E. Horton, AIAA, New York, 1982, pp.248-272.

23. Stewart, D. A., Rakich, J. V., and Lanfranco, M. J., "Catalytic Surface Effects of Space Shuttle Thermal Protection System During Earth Entry of Flights STS-2 through STS-5," Paper presented at Langley Conference on Shuttle Performance: Lessons Learned, Hampton, Va., March 1983.

24. Rakich, J. V., Stewart, D. A., and Lanfranco, M. J., "Results of a Flight Environment on the Catalytic Efficiency of the Space Shuttle Heat Shield," AIAA Paper 82-0944, June 1982.

25. Marichalar, J.J., Rochelle, W.C., Kirk, B.S., Campbell, C.H., "BLIMPK/Streamline Surface Catalytic Heating Predictions on the Space Shuttle Orbiter", AIAA 2006-180, January 2006.

26. Wood, W. A., Oliver, A. B., "Assessment of CFD for HypersonicTurbulent Heating Rates," $42^{\text {nd }}$ Thermophysics Conference, American Institute of Aeronautics and Astronautics, Reston, VA (submitted for publication)

27. Stephani, K.A., Goldstein, D.B., Varghese, P.L., "Effects of Rarefaction on Hypersonic Boundary Layer Flow over Discrete Surface Roughness", AIAA 2010-456, January 2010. 